\title{
Arc-Plasma Reduction of Some Refractory Metal Oxides
}

\author{
K. Taniuchi
}

Harigaya 1-13-14, Urawa City, Saitama-Ken, Japan 338

\section{CONTENTS}

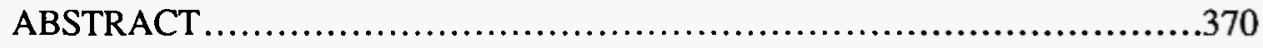

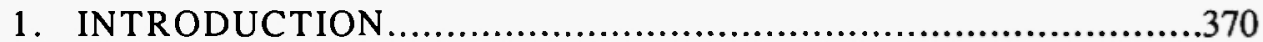

2. THE APPARATUS .................................................. 371

3. ARC-PLASMA REDUCTION OF VANADIUM

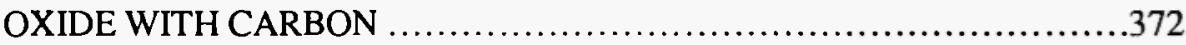

A. Experimental Methods ..............................................372

B. Results and Discussion ...............................................374

4. ARC-PLASMA REDUCTION OF TANTALUM OXIDE

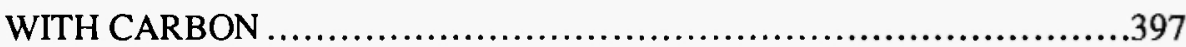

A. Experimental Methods ...............................................399

B. Results and Discussion ...............................................400

5. CONCLUSIONS ......................................................410

ACKNOWLEDGEMENT ............................................4 412

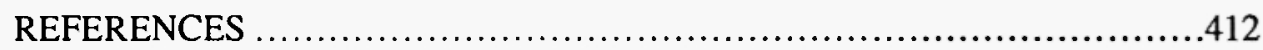




\section{ABSTRACT}

The carbon reduction of vanadium oxide and tantalum oxide has been investigated in a plasma arc-furnace.

The sample was a mixture of graphite and each pentoxide, vacuum pressed into a briquette and weighing $3.5 \mathrm{~g}$ for vanadium and $7 \mathrm{~g}$ for tantalum. The reduction temperature of $2100^{\circ} \mathrm{C}$ for vanadium and of $3100^{\circ} \mathrm{C}$ for tantalum were adopted. About 10 minutes of the reaction time is almost enough because the reduction proceeds rapidly in an early stage and the products reach the maximum content of metals.

Argon and an $\mathrm{Ar}-\mathrm{H}_{2}$ mixture $\left(5 \sim 25\right.$ vol. $\left.\% \mathrm{H}_{2}\right)$ were used as the plasma-arc gas.

The optimum mixing ratio of carbon and vanadium pentoxide, $\mathrm{C} / \mathrm{V}_{2} \mathrm{O}_{5}$ is $4.10 \sim 4.50$ and is smaller than the stoichiometric ratio of 5 . In the case of pure argon arc-gas, the product of vanadium content reaches a maximum $96 \%$. This crude vanadium was refined with $\mathrm{Ar}-\mathrm{H}_{2}$ arc-gas. In this second step, vanadium content reaches $99.6 \%$. In the case of tantalum, the optimum mixing ratio of carbon and tantalum pentoxide, $\mathrm{C} / \mathrm{Ta}_{2} \mathrm{O}_{5}$ is $5.10 \sim 5.15$ and is somewhat greater than the stoichiometric ratio of 5 . Within 10 minutes of the reaction time, the maximum tantalum content reaches $99.9 \%$.

Based on these results, plasma-arc reduction is considered to be a useful process for massive refractory metals such as V. Ta, etc.

\section{INTRODUCTION}

The smelting process of metals by carbon reduction of metal oxides is the most common process and has been used since ancient times.
But the upper limit of the reaction temperature is about $2000^{\circ} \mathrm{C}$, and in most cases of ferrous and non-ferrous metal smelting, temperature ranges of $1000 \sim 1800^{\circ} \mathrm{C}$ are used.

In the case of plasma-arc heating, the central flame temperature is over $10000^{\circ} \mathrm{K}$. When we use this plasma-arc furnace for metal smelting, it is easy to heat the raw materials over $2000^{\circ} \mathrm{C}$. We think that attachments of $2000-3500^{\circ} \mathrm{C}$ (and more widely, up to $5000^{\circ} \mathrm{C}$ ) of the reaction temperature are able to be utilized. Then the melting down of refractory metals such as W (M.P. $3400^{\circ} \mathrm{C}$ ) $/ 1 /$. Ta (M.P. $2990^{\circ} \mathrm{C} / 1 /$ and Mo (M.P. $2620^{\circ} \mathrm{C}$ ) $/ 1 /$ is possible in the plasma-arc furnace.

In the case of carbon reduction of metal oxides, $\mathrm{M}_{\mathrm{x}} \mathrm{O}_{\mathrm{y}}$, the value of the standard free energy of reaction, $\Delta \mathrm{G}^{\circ}$. increases in proportion to the increase in heating temperature. That is, for many kinds of metal oxides, the value of $\Delta G^{\circ}$ changes from a minus value to a plus with an increase ir temperature. On the other hand, $\Delta G^{\circ}$ of $\mathrm{CO}$ gas shifts to a larger minus value in proportion to the increase in reaction temperature.

The equilibrium of the following reaction

$$
\mathrm{MxOy}+\mathrm{yC} \rightleftharpoons \mathrm{xM}+\mathrm{yCO}
$$

moves to the right with an increase in temperature Then the increase in reaction temperatur. accelerates the reaction velocity and is profitabl for metal reduction.

Fig. 1 shows the changes in standard fre energy, $\Delta G^{\circ}$, with the temperature for the reaction of some refractory metal oxides and CO gas. Thi: figure shows that reduction of almost all metc oxides with carbon is possible at a temperature $c$ more than two thousand and several hundre degrees centigrade. 


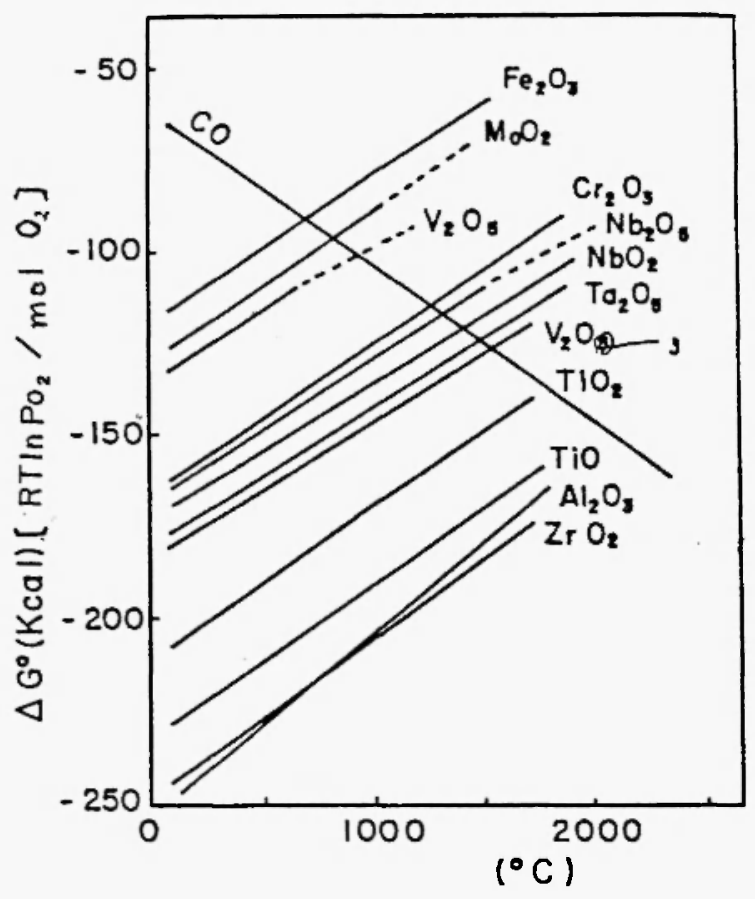

Fig. 1 Standard free energy of reaction of isome metal oxides

The reduction of the oxides $\mathrm{Al}, \mathrm{Mg}$, and $\mathrm{T}$ with carbon are considered to be difficult with an ordinary smelting furnace but the use of the plasma-arc furnace is expected to be very profitable/2/.

In the cases of $\mathrm{Al}$ or $\mathrm{Mg}$, the reduction product is considered to be metal vapor. "The shock cooling" or "the rapid quenching" /3/ is an essential process for separation of the metal products and $\mathrm{CO}$ gas and also for prevention of reoxidation.

Recent developments in the technology of the plasma-arc furnace have led to many studies on reduction of metallic compounds, production of alloys, and formation of carbides or nitrides at high temperatures $/ 4 / 5 /$.

We have carried out several investigations on the arc-plasma reduction of metallic compounds. These compounds have high melting points or are refractory in nature and are found to be difficult to reduce.

In this paper, our results on carbon reduction of vanadium pentoxide and tantalum oxide are presented.

\section{THE APPARATUS}

A plasma-arc furnace of Toel Industry Co. Ltd. was used. This furnace is a direct current, arcplasma type and has a maximum power output of $20 \mathrm{KW}$. Fig. 2 shows the schematic diagram of the furnace including the plasma torch and the reaction vessel. The reaction vessel is a cylinder of stainless steel. Its Inner diameter and height are $26 \mathrm{~cm}$ and $20 \mathrm{~cm}$, respectively. The diameter of the copper nozzle (anode) $1 \mathrm{~s} 0.7 \mathrm{~cm}$.

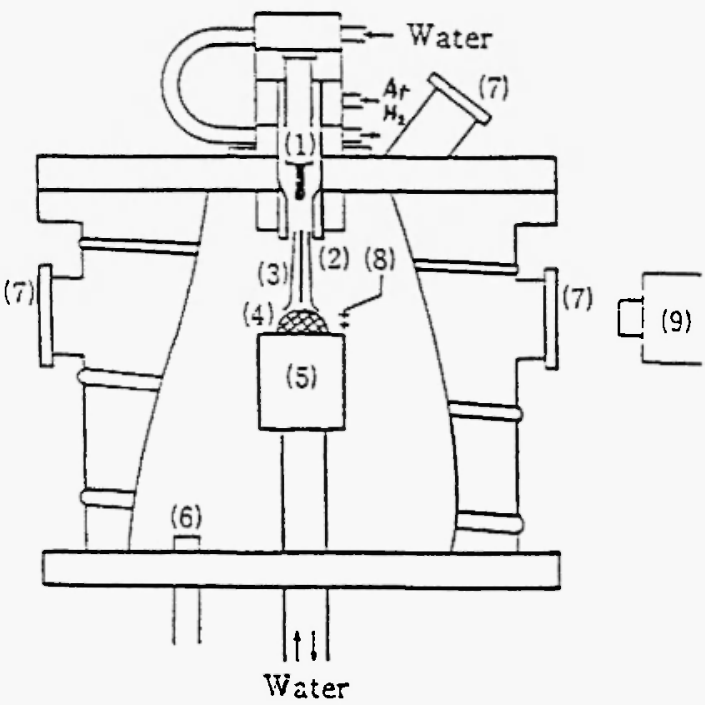

Fig. 2 Schematic diagram of the plasma-arc furnace.

1) Cathode ( $\left.\mathrm{W}+\mathrm{ThO}_{2}\right)$, 2) Anode (Copper nozzle), 3) Plasma flame, 4) Sample, 5) Copper crucible, 6) Gas outlet, 7) Vlewing port, 8) Radiation sealed molybdenum plate with small hole $(2 \mathrm{~mm} \times 2 \mathrm{~mm})$, 9) Two-color-eye pyrometer 
Sample materials in a water-cooled, copper crucible are reduced by the transferred type arc. The distance between the top of the plasma torch and the sample is about $2 \mathrm{~cm}$.

The surface temperature of the sample materials during reduction is measured by a Sigma Electron Industrial Co. Ltd., Type C-120, two-color. optical pyrometer. The upper limit of this measuring device is $3300^{\circ} \mathrm{C}$. Upon entering the pyrometer, radiation from the high temperature plasma flame causes a full scale deflection of the indicator. Therefore, the surface temperature of the sample cannot be measured. Consequently, a molybdenum plate with a $2 \mathrm{~mm}$ by $2 \mathrm{~mm}$ size hole is attached to the edge of the copper crucible in order to prevent the incidence of radiation from the plasma flame (see Fig. 2). To ensure the accuracy of the pyrometer. the melting temperatures of tantalum (M.P. $2990^{\circ} \mathrm{C} / 1 /$. purity $\left.99.9 \%\right)^{1}$ and niobium (M.P. $2520^{\circ} \mathrm{C} / 1 /$, purity $99.5 \%$ ) have been measured and are found to be $3100^{\circ} \mathrm{C}$ and $2550^{\circ} \mathrm{C}$. respectively. Therefore, this pyrometer is confirmed to be reasonably accurate.

\section{ARC-PLASMA REDUCTION OF VANADIUM OXIDE WITH CARBON}

Metallic vanadium is used as an alloying element in alloy steels and construction material of atomic reactors. However, in Japan the production of this metal is very limited at present/6/. Ordinary smelting processes involve the reduction of oxide or chloride with calcium or magnesium metals/7,8/ and the thermal decomposition of iodide/9/.

1. Compositions are shown in weight percentage hereafter, unless specified otherwise.
As for the reduction of oxide with carbon. experimental reports are few except for the study of reduction in the solid state under a reduced carbon monoxide pressure of approximately $1600^{\circ} \mathrm{C} / 10,11 /$. We have carried out an investigation of the arc-plasma reduction of vanadium pentoxide with carbon, and our results are presented in this paper. Even though arcplasma reduction of vanadium oxide has already been reported by Akashi et al, /12/, we feel that a sufficient explanation has not been made.

\section{A Experimental Methods}

The vanadium oxide used in the present work is powdered pentoxide of $99.56 \%$ purity with a particle size of minus 200 mesh. The reduced reagent is graphite powder of minus 300 mesh particle size and its ash content is under $0.05 \%$. Selected ratios of the two materials are mixed for about 2 hours. These mixtures are vacuum briquettes under a pressure of 6 ton $/ \mathrm{cm}^{2}$. Each briquette is about $15 \mathrm{~mm}$ diameter and about 7 to $8 \mathrm{~mm}$ in thickness and weighs $3.5 \mathrm{~g}$.

The fundamental reaction of reduction is shown as follows:

$$
\mathrm{V}_{2} \mathrm{O}_{5}+5 \mathrm{C}=2 \mathrm{~V}+5 \mathrm{CO}
$$

Then the stoichiometric mixing ratio of carbon to vanadium pentoxide, $\mathrm{C} / \mathrm{V}_{2} \mathrm{O}_{5}$, is 5 . However, in order to find the optimum mixing ratio. the reduction of briquettes with the mixing ratios of 3 to 6 has been studied. Furthermore, two kinds of briquettes have been compared. One is a green briquette and the other is sintered at 700 $1000^{\circ} \mathrm{C}$ for 1 hour in an argon atmosphere prior to reduction. 
Industrial high purity argon is used in the generation of the plasma arc and the gas flow rate is $51 / \mathrm{min}$. The relationships between the arc current, the arc voltage, the power input of the furnace and the surface temperature of the sample are shown in Fig. 3.

The reduction temperatures in this study range from 2100 to $2800^{\circ} \mathrm{C}$. The melting temperature of metallic vanadium is reported to be $1890^{\circ} \mathrm{C} / 1 /$. Further changes in the standard free energy with temperature for the reaction of various vanadium oxides /13/ are shown in Fig. 4. Thus, the reaction temperatures in this work are considered to be sufficient for the carbothermic reduction of vanadium oxide.

The time spent to melt down the briquette is approximately 45 seconds. It should be noted that in this work, the instant when the briquette is fused and forms a liquid button is considered to be the starting time of the reaction. After this time. the reaction is continued for a given number of minutes, the sample material is turned over. and the reduction is continued for an equal time interval. The total time of both heat treatments is given as the reaction time.

$\mathrm{X}$-ray diffraction analyses, Vickers hardness measurements. microscopic observations, and EPMA analyses for the reduction products have been carried out. The content of vanadium is analyzed by chelatometry and the remaining carbon is analyzed by the method of coulometric

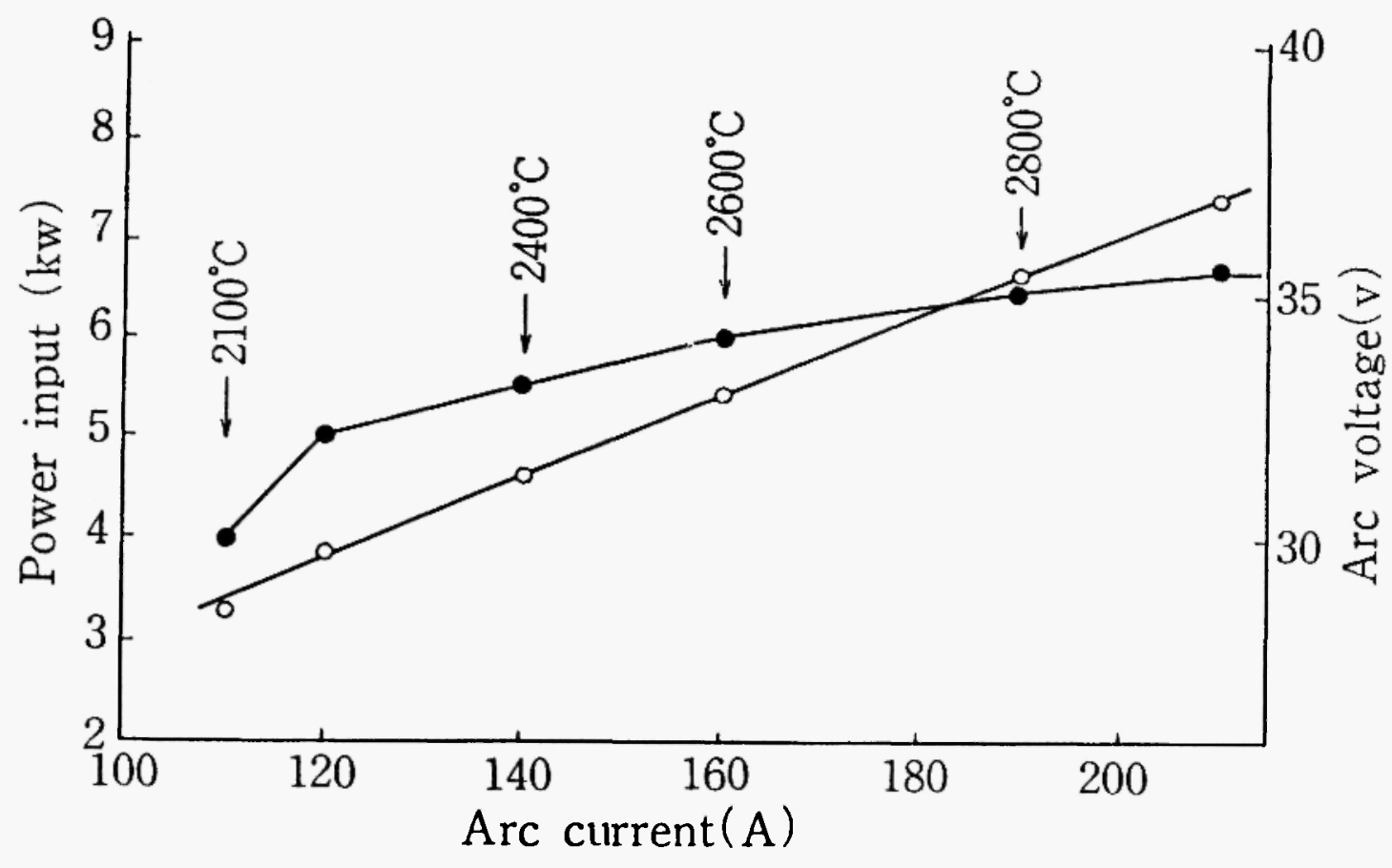

Fig. 3 Correlation between the arc current, the arc voltage and the power of input of the plasma-arc furnace ( -o- : power input, - - : arc voltage, the flow rate of Ar gas $=5[1 / \mathrm{min}])$ 


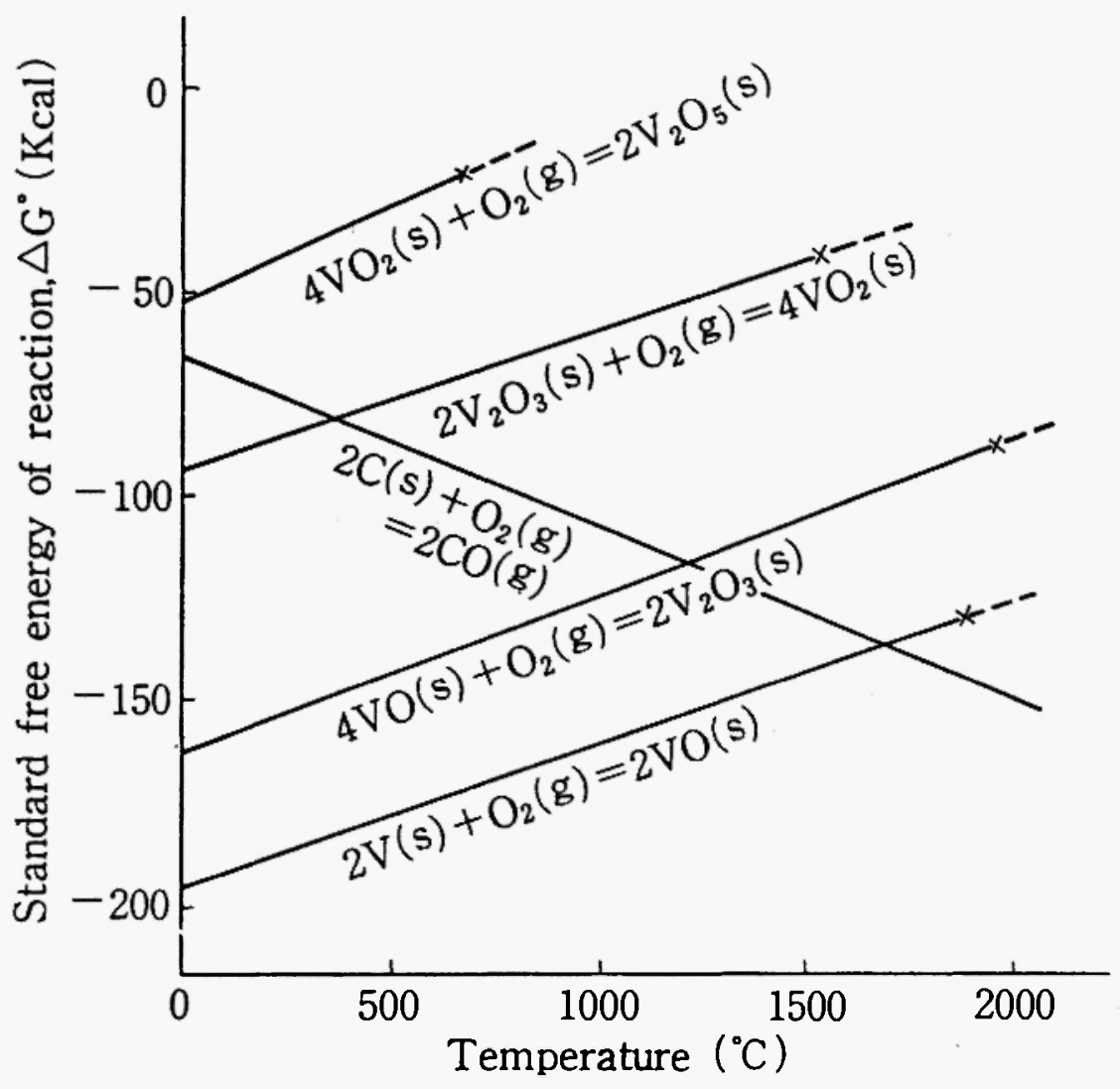

Fig. 4 Changes in standard free energy with temperature for the reaction of vanadium oxides (Kubaschewski et al.)

determination. The remaining oxygen is calculated by using the following equation:

$$
O(w t . \%)=100-V-C
$$

To confirm the accuracy of the calculated quantity, oxygen of two sample products has been analyzed by the method of argon gas fusion-coulometric determination. These results are shown in Table 1. Because the results from the chemical analysis agree well with the calculated values, the calculated values from the above-mentioned equation are to be reasonable.
B. Results and Discussion

B.1. Ftrst step reduction lobtaining the crude vanadium product by Ar-plasma arc)

The appearance of the briquette at various stages in the plasma-arc treatment can be examined in Photo. 1. The briquette sintered for 1 hours at $1000^{\circ} \mathrm{C}$. Photo. $\mathrm{l}(\mathrm{B})$, is darker than the green briquette, Photo. 1(A). The top and crosssectional views of a green briquette treated with the plasma-arc for 30 seconds is shown in Photo. 1(C). The upper section of the sample adjacent to the plasma flame has undergone reduction to a 
TABLE 1

Analysis of V. C and $\mathrm{O}$ of the Products

\begin{tabular}{|c|c|c|c|}
\hline Sample & $\mathrm{V}(w t \%)$ & $\mathrm{C}(w t \%)$ & $\mathrm{O}(w t \%)$ \\
\hline 1 & 93.5 & 3.5 & 2.7 \\
2 & 95.8 & 2.5 & 1.2 \\
\hline
\end{tabular}

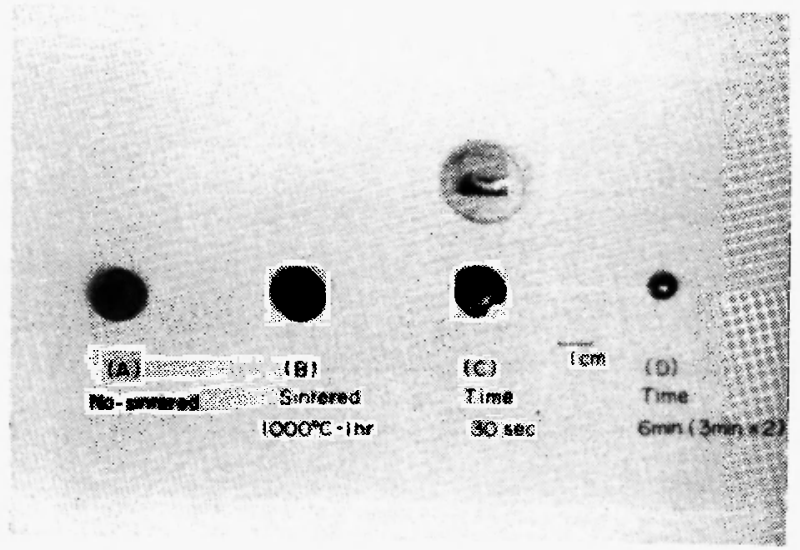

Photo. 1 Photographs of the sample materials before and after the plasma-arc treatment:
A) Not sintered
B) Sintered $1 \mathrm{hr}$ at $1000^{\circ} \mathrm{C}$
C) Treated for 30 sec. upper photo-
graph shows the vertical cross section
D) Sample heated for $6 \mathrm{~min}$. after the melting down (that is, reaction time $6 \mathrm{~min}$.)

large extent. This portion has a metallic luster and appears as a much lighter phase in the photograph. Small pores are observed near the interface between the light and dark reglons and are considered to be due to bubbles of $\mathrm{CO}$ gas generated by the reduction reaction. A sample reduced for 6 minutes forms a metallic button (see Photo. 1(D).

\section{B1.1. The effect of the mixing ratio, $\mathrm{C} / \mathrm{V}_{2} \mathrm{O}_{5}$}

Vanadium has various valencles from 2 to 5 and has a strong affinity for carbon and oxygen. To find the most suitable reducing condition, the mixing ratio, $\mathrm{C} / \mathrm{V}_{2} \mathrm{O}_{5}$, in the briquettes has been varied from 3 to 6 . Fig. 5 shows the dependence of vanadium, carbon and oxygen contents of the reduction products on the ratio, $\mathrm{C} / \mathrm{V}_{2} \mathrm{O}_{5}$, at a reaction temperature of $2100^{\circ} \mathrm{C}$. The results for three reaction times, 0,6 and 20 minutes, are shown in this figure. The curves indicating the residual carbon and oxygen correspond to a reaction time of 20 minutes. The optimum mixing ratio is approximately 4.5 which is somewhat less than the stolchiometric ratio of 5 (see FIg. 5). Additionally, the highest vanadium content of the product reaches $95.9 \%$ after 20 minutes of reaction. The contents of the residual carbon and oxygen in this product are $2.3 \%$ and $1.8 \%$, respectively. When the $\mathrm{mixing}$ ratio is less than 4 , the residual oxygen in the product increases due to the shortage of carbon for reduction. Conversely, when the mixing ratio exceeds 5 , the presence of excess carbon leads to the formation of vanadium carbide in the reaction product. When the mixing ratio is 6 , the peak for the carbide, $\mathrm{V}_{8} \mathrm{C}_{7}$, is observed in the X-ray diffraction pattern of the product and the postulation of carbide formation 


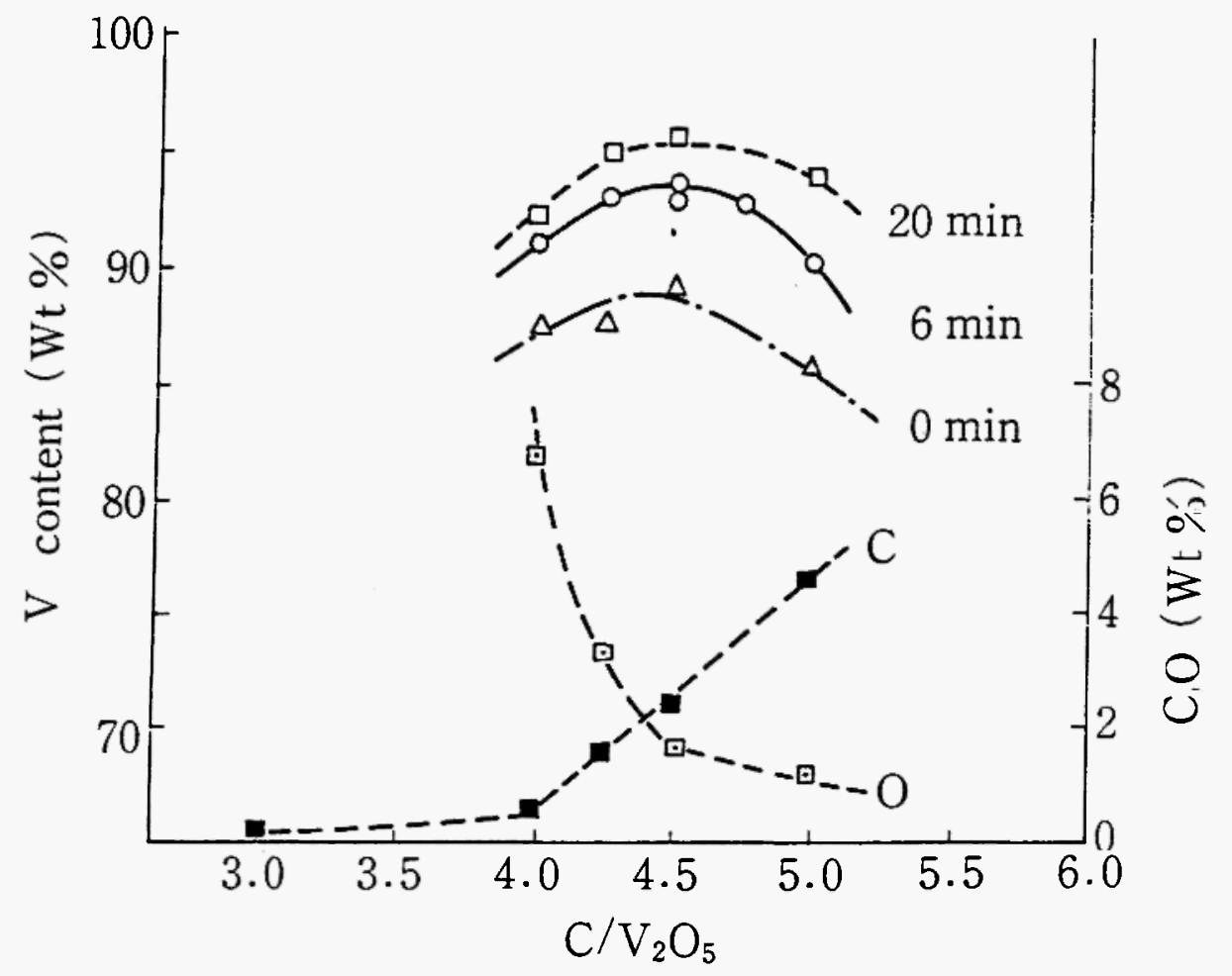

Fig. B Dependence of $\mathrm{V}, \mathrm{C}$ and $\mathrm{O}$ contents of the products on $\mathrm{C} / \mathrm{N}_{2} \mathrm{O}_{5}$ at $2100^{\circ} \mathrm{C}$ (not sintered)

by excess carbon is confirmed. As a result of the above-mentioned discussion, the optimum mixing ratio is considered to be approximately 4.5 .

Furthermore, the vanadium content of the product approaches $90 \%$ at the reaction time of zero (see Fig. 5). Since the initial content of vanadium in the briquette is about $43 \%$, the reduction of the briquette proceeds rapidly before the sample is completely molten. During this period, the reduction reaction of liquid vanadium oxide with solid carbon is considered to proceed rapidly.

\section{B.1.2. The effect of preltminary stnterting}

Preliminary sintering of the briquette prevents the sample material from scattering during plasma-arc heating. Moreover, the electrical conductivity of the briquette increases which helps to stabilize the plasma flame. While the recovery of vanadium from the green briquette is $86 \sim 88 \%$, the briquette sintered for 1 hour at $1000^{\circ} \mathrm{C}$ in an argon atmosphere shows an increase in its recovery to $94-95 \%$ for a mixing ratio between 4 and 5. However, when the mixing ratio is less than 4 or greater than 5.5, both kinds of briquettes show a decrease in vanadium recovery due to the increased loss in the sample. In both these cases, the shape of the liquid sample is not spherical and a disc-shaped product is formed possessing a rough surface.

Peaks of $\mathrm{V}_{2} \mathrm{O}_{4}$ and $\mathrm{C}$ and peaks of $\mathrm{V}_{2} \mathrm{O}_{3}$ and 
$\mathrm{C}$ are observed in the $\mathrm{X}$-ray diffraction patterns of briquettes sintered for 1 hour at $700^{\circ} \mathrm{C}$ and at $1000^{\circ} \mathrm{C}$, respectively. Therefore, the reduction is considered to begin during preliminary sintering. Furthermore, the losses in weight during sintering are 10 to $11 \%$ at $700^{\circ} \mathrm{C}$ and 20 to $21 \%$ at $1000^{\circ} \mathrm{C}$ and correspond to the above-mentioned peaks in the $\mathrm{X}$-ray diffraction patterns.

For the briquette sintered for 1 hour at $1000^{\circ} \mathrm{C}$ and reduced at $2100^{\circ} \mathrm{C}$. Fig. 6 shows the dependence of $\mathrm{V}, \mathrm{C}$ and $\mathrm{O}$ contents of the products on the ratio $\mathrm{C} / \mathrm{N}_{2} \mathrm{O}_{5}$, in the same manner as in Fig. 5. In this case, the results are similar to those obtained for green briquettes. The optimum mixing ratio is again approximately 4.5 and the maximum vanadium content attained is $95.3 \%$. However, the residual carbon content in the product Increases slightly while the residual oxygen decreases. The reason for this phenomenon is considered to be that the oxygen content diminishes in the sintering steps and, correspondingly, some carbide is formed. However. presence of carbide is not confirmed by $X$-ray diffraction analysis of the sintered briquette.

\section{B.1.3 The effect of reduction temperature and reaction time}

By increasing the power input to the plasmaarc, the reaction temperature is raised from $2100^{\circ} \mathrm{C}$ to $2800^{\circ} \mathrm{C}$ and the effect of temperature on improving the content of vanadium in the product

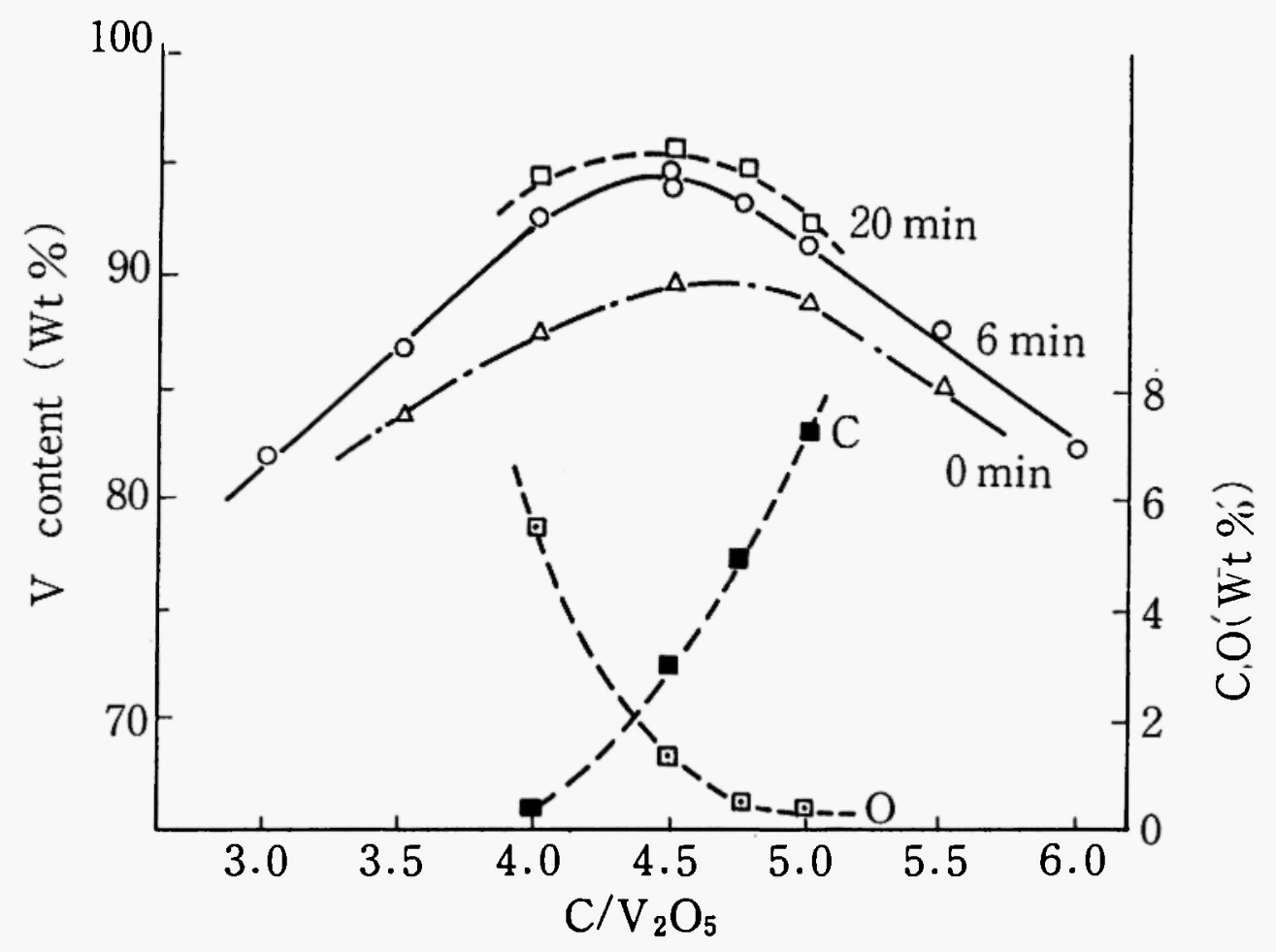

Fig. 6 Dependence of $\mathrm{V}, \mathrm{C}$ and $\mathrm{O}$ contents of the products on $\mathrm{C} / \mathrm{V}_{2} \mathrm{O}_{5}$ at $2100^{\circ} \mathrm{C}$ (sintered $1 \mathrm{hr}$ at $1000^{\circ} \mathrm{C}$ ) 


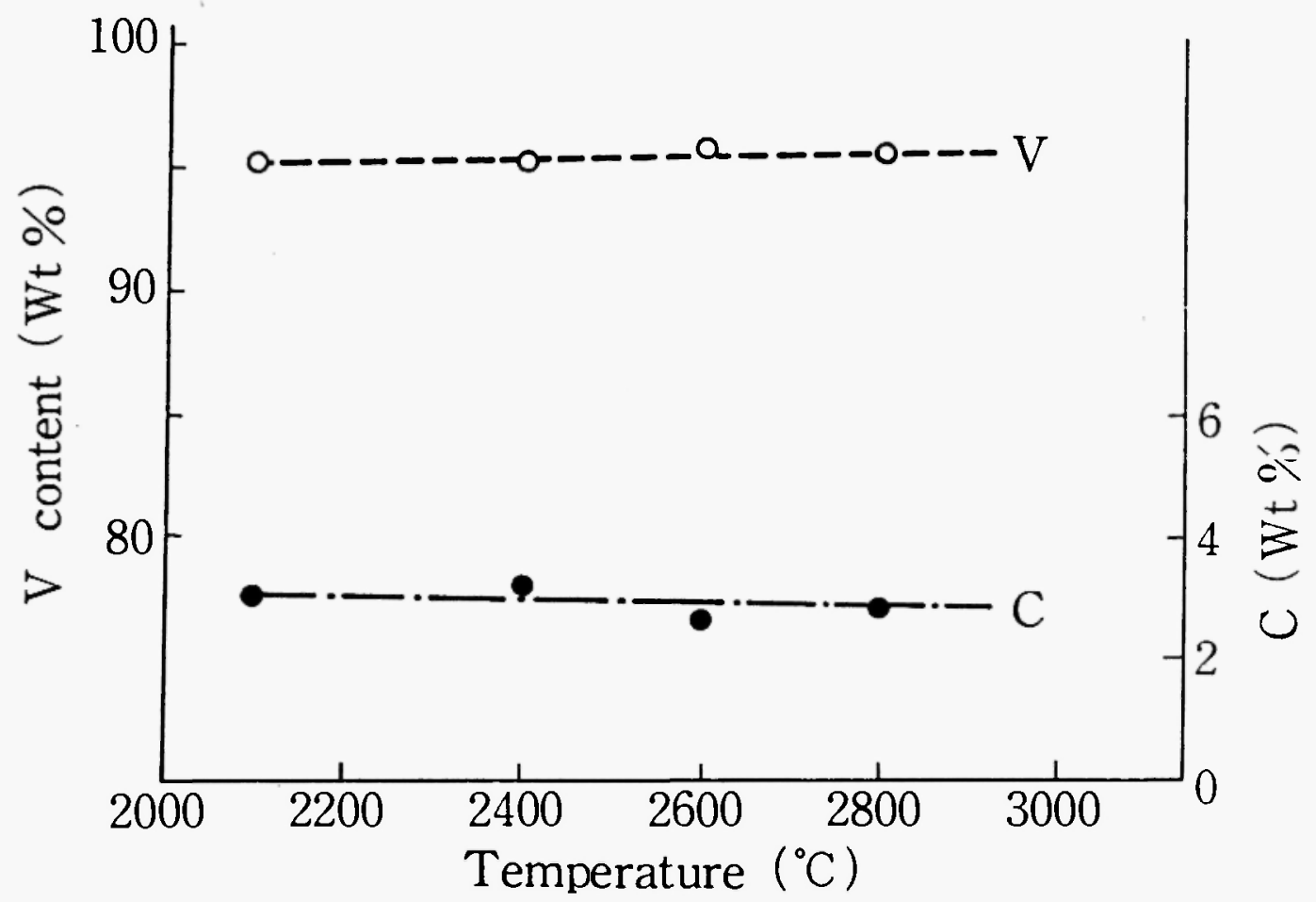

Fis. 7 Reduction temperature dependence of $\mathrm{V}$ and $\mathrm{C}$ contents of the products $\left(\mathrm{C} / \mathrm{V}_{2} \mathrm{O}_{5}\right.$ 4.5, sintered $1 \mathrm{hr}$ at $1000^{\circ} \mathrm{C}$, time $10 \mathrm{~min}$ )

is observed. The results are shown in Fig. 7. In this figure, the abscissa and the ordinate indicate the reaction temperature and the vanadium or carbon content, respectively. In this study, the samples with a mixing ratio of $\mathbf{4 . 5}$ are sintered for 1 hour at $1000^{\circ} \mathrm{C}$ and are reduced for 10 minutes. When the reaction temperature is raised, the sample in the crucible vibrates violently and the reduction rate is expected to be enhanced by this agitation. However, as shown in the figure, the enhancement of the reaction by Increasing the temperature above $2100^{\circ} \mathrm{C}$ is not observed in the vanadium content. Also the $\mathrm{X}$-ray diffraction pattern does not change. Based on these results, it can be stated that the majority of the reduction occurs at $2100^{\circ} \mathrm{C}$.
The dependence of the vanadium, carbon and oxygen contents of the products on the reaction time is shown in Fig. 8. These results are for briquettes with a mixing ratio of 4.5 reduced at $2100^{\circ} \mathrm{C}$. As described earlier, the sample melts and forms a button within 45 seconds upon application of the plasma-arc. During this period the reduction of vadium oxide proceeds rapidly and the vanadium content approaches $90 \%$. Subsequently, the reduction proceeds slowly for about 10 minutes and the vanadium content increases to approximately 96\%. Correspondingly, the carbon and oxygen contents decrease. When the reaction time exceeds 10 minutes, further reduction of the oxide does not occur. The remaining carbon and oxygen contents also do not 


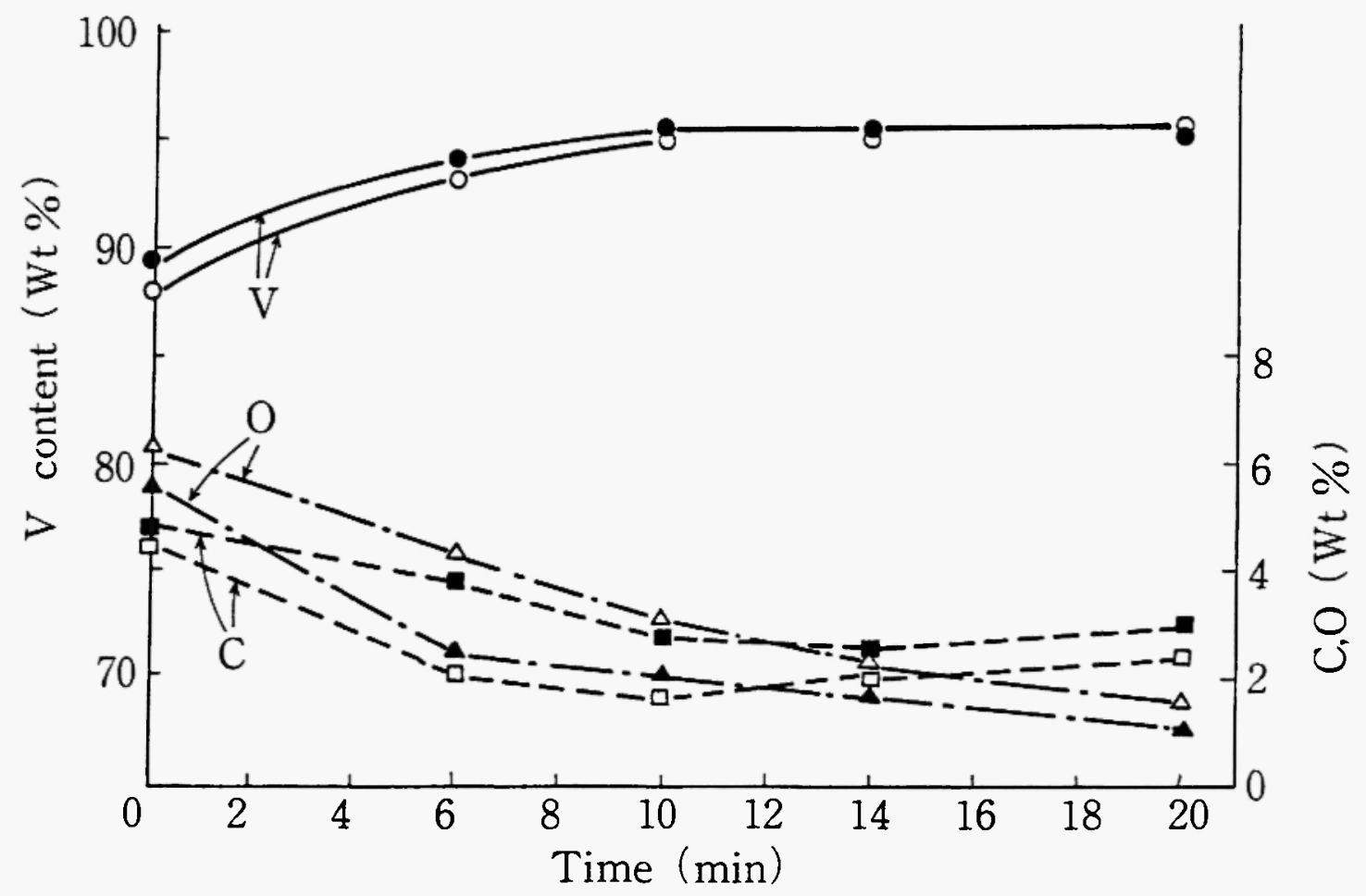

Fig. 8 Dependence of $\mathrm{V}, \mathrm{C}$ and $\mathrm{O}$ contents of the products on the reaction time at $2100^{\circ} \mathrm{C}\left(\mathrm{C} / \mathrm{V}_{2} \mathrm{O}_{5} 4.5, \mathrm{o}, \Delta, \mathrm{a}\right.$ : not sintered, $\bullet, \mathrm{a}, \mathrm{a}$ : sintered $1 \mathrm{hr}$ at $\left.1000^{\circ} \mathrm{C}\right)$

decrease below certain limits. Stagnation of the reduction process after the melt down period is considered to be caused by the following effect. When the contents of carbon and oxygen dissolved in molten iron are small and the pressure of carbon monoxide is kept constant, Hamilton's equation holds between the carbon and oxygen contents as follows /14/:

$$
\text { [C] }[\mathrm{O}]=\mathrm{K}
$$

For the melts studied in this work, the above equation is confirmed to be valid (see Fig. 9). The curve Indicating the relationship between the carbon and oxygen contents of the products which have a mixing ratio of 4 to 5 and a reduction time of
20 minutes at $2100^{\circ} \mathrm{C}$ is almost hyperbolic. Using these values of carbon and oxygen contents in weight percentages, the calculations of the constant, $K$, by the least squares method gives the following relationship:

$$
[\mathrm{O}]=3.82[\mathrm{C}]^{-1.09}
$$

In this case the correlation coefficient is calculated to be 0.98 . In this experiment, the pressure of $\mathrm{CO}$ around the sample is considered to be small because argon gas is injected into the furnace and flows at a high flow rate. Nevertheless. the pressure of $\mathrm{CO}$ is estimated to be sufficient to disturb the advance of the reduction to some extent.

The values of the carbon and oxygen contents 


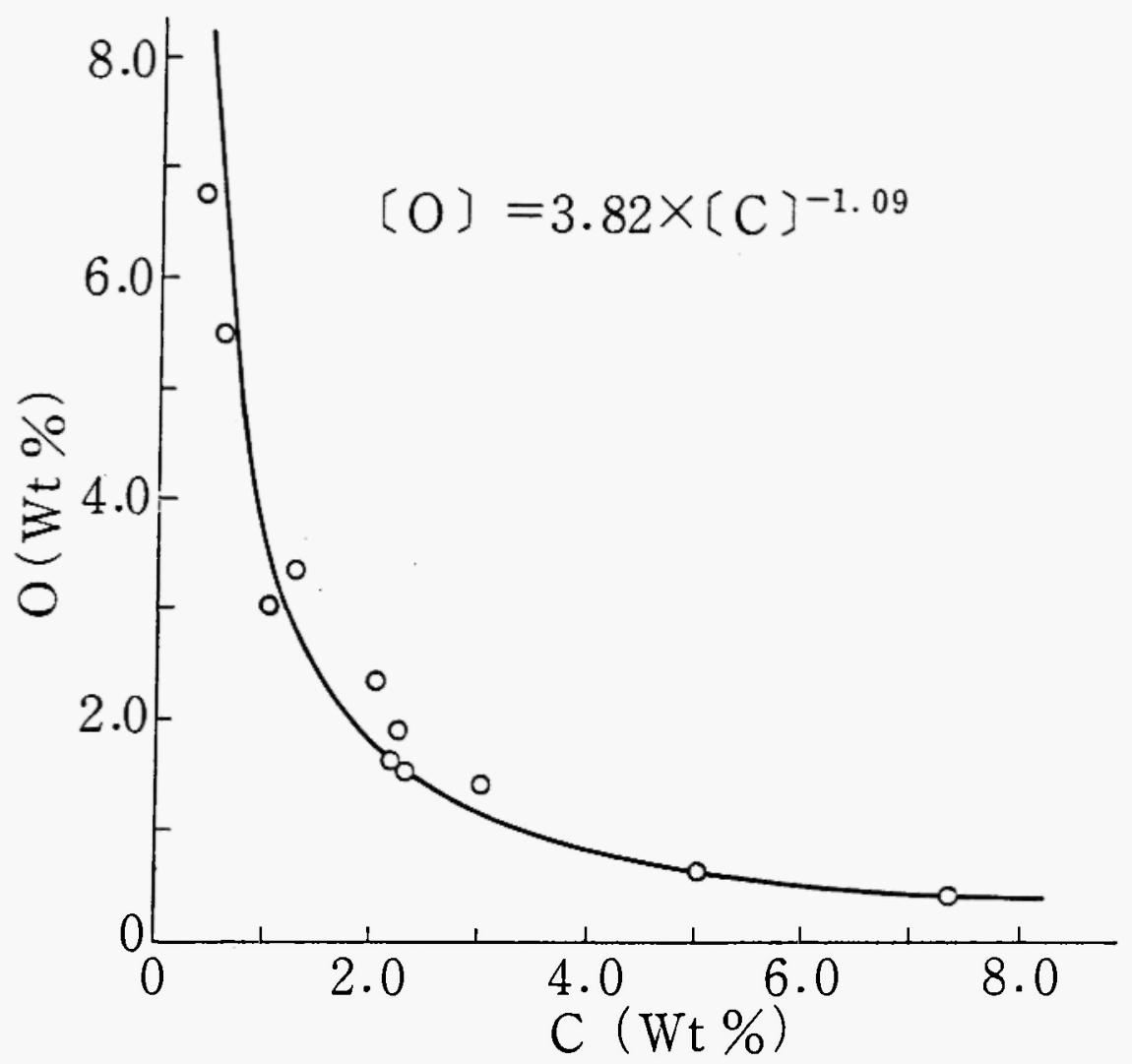

Fig. 9 Relation between $\mathrm{C}$ and $\mathrm{O}$ contents of the products at $2100^{\circ} \mathrm{C}$ (reaction time $20 \mathrm{~min}$ )

in Fig. 9 are large compared to those of molten Iron. One reason for this is considered to be the strong affinity of vanadium for carbon and oxygen $115 /$. Therefore, some doubt still remains as to the validity of using Hamilton's equation in this case.

\section{B.1.4. X-ray diffraction analysis of the reduction product}

The reduction product is ground into powder and $\mathrm{X}$-ray diffraction patterns are obtained. The patterns for green briquettes reduced for 20 minutes at $2100^{\circ} \mathrm{C}$ are presented in Fig. 10. As shown in this figure, the strongest vanadium peaks and the weakest carbide, $\mathrm{V}_{2} \mathrm{C}$, peaks are obtained when the mixing ratio is 4.5 . When the mixing ratio increases to almost 5.5, the peaks of $\mathrm{V}_{2} \mathrm{C}$ are intensiffed substantially. Furthermore, when the ratio exceeds 6 , the peaks of the carbide, $\mathrm{V}_{8} \mathrm{C}_{7}$. which contains more carbon than $\mathrm{V}_{2} \mathrm{C}$ are observed. When the mixing ratio decreases and approaches 4, the locations of the peaks are shifted slightly from those of vanadium. This shift is attributed to the strains produced on the lattice by the presence of relatively large quantities of carbon and oxygen.

When sintered briquettes are reduced, the $\mathrm{X}$ ray diffraction patterns show similar tendencles to those observed for green briquette reductions. However, the former case results in a relative 


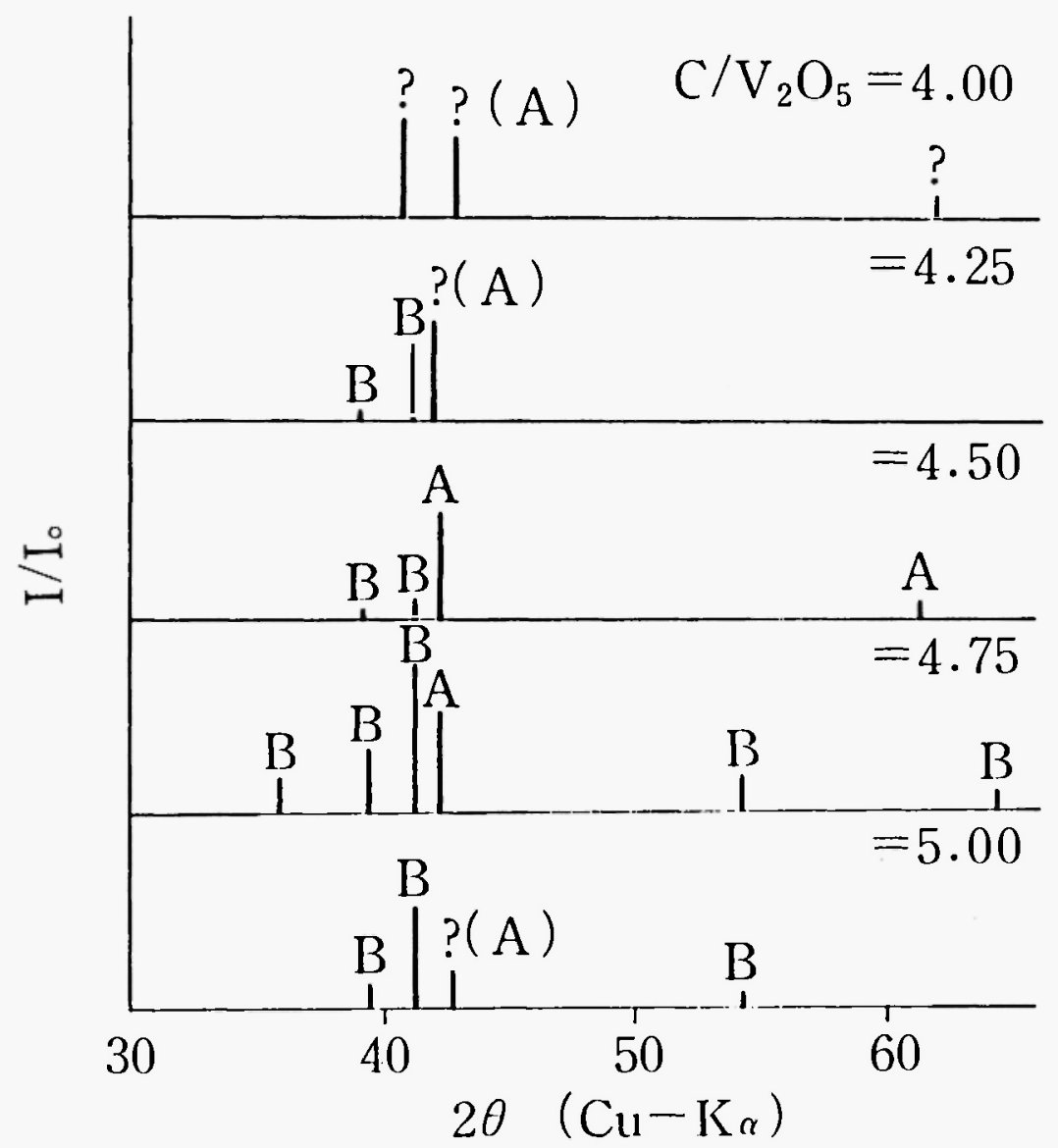

Fig. 10 Dependence of the $X$-ray diffraction pattern on $\mathrm{C} / \mathrm{V}_{2} \mathrm{O}_{5}$ (not sintered, temperature $2100^{\circ} \mathrm{C}$, time $20 \mathrm{~min}$ ) (A:V, B:V $\mathrm{V}_{2} \mathrm{C}$ )

Increase in the intensity of the peaks of $\mathrm{V}_{2} \mathrm{C}$.

Fig. 11 shows the relationship of the $X$-ray diffraction pattern and the reaction time. Green briquettes with a mixing ratio of 4.5 have been reduced at $2100^{\circ} \mathrm{C}$ for 0,6 and 20 minutes. Increasing the reaction time results in stronger vanadium peaks and a gradual decrease in the peaks of $\mathrm{V}_{2} \mathrm{C}$. These results trace the advancement of the reduction with reaction time. However, it is difficult to clearly define the difference between the patterns for the reaction times of 20 minutes and 6 minutes. Thus, an increase in the reaction time does not result in substantial improvements in the product's vanadium content.
These findings coincide with the results of the chemical analyses described above. A similar tendency is observed for sintered briquettes.

\section{B.1.5. Reduction product hardness measurements}

The hardness of metals such as V. Nb and Ta increases rapidly when small quantities of carbon or oxygen are present.

The Vickers hardness of the products reduced at $2100^{\circ} \mathrm{C}$ was measured. Fig. 12 shows the dependence of the hardness of the products on the mixing ratio. The minimum hardness number 


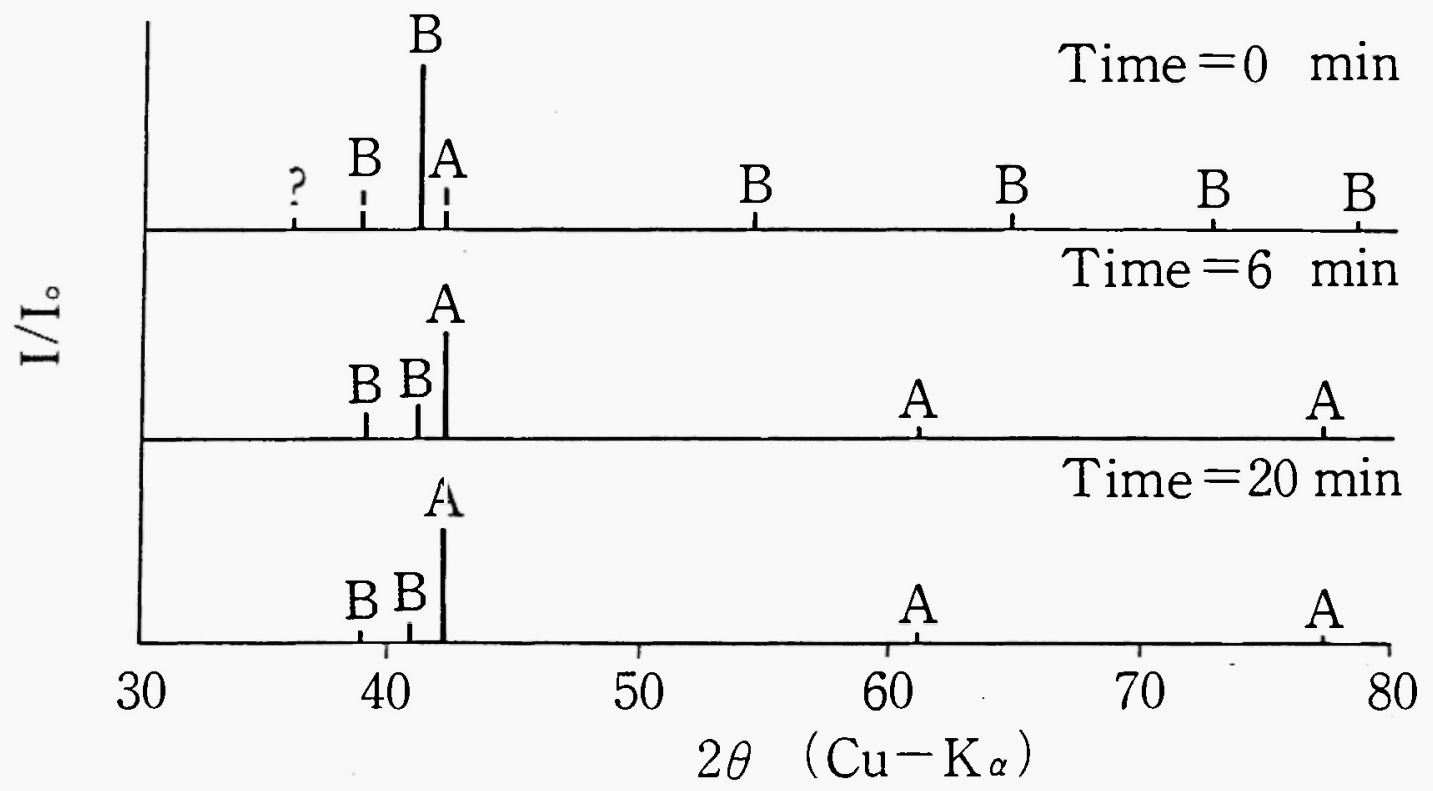

Fig. 11 Dependence of the $X$-ray diffraction pattern on the reaction time $\left(\mathrm{C} / \mathrm{V}_{2} \mathrm{O}_{5} 4.5\right.$, not sintered, temperature $\left.2100^{\circ} \mathrm{C}\right)\left(\mathrm{A} \cdot \mathrm{V}, \mathrm{B}: \mathrm{V}_{2} \mathrm{C}\right)$

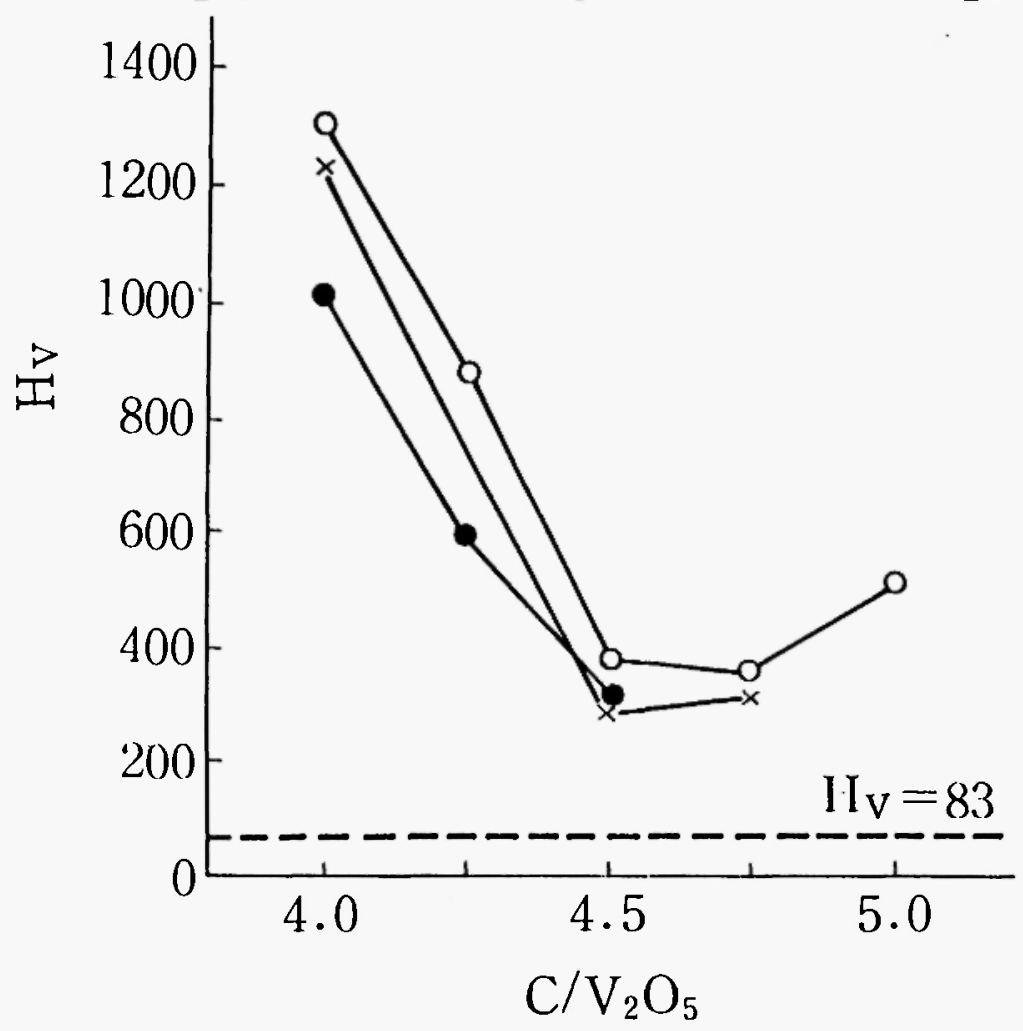

Fig. 12 Dependence of Vickers hardness of the products on $\mathrm{C} / \mathrm{V}_{2} \mathrm{O}_{5}$ (temperature $\quad-0-$ : not sintered - $\mathbf{x}-$ : sintered $1 \mathrm{hr}$ at $\left.700^{\circ} \mathrm{C}\right),-\infty$ : sintered $1 \mathrm{hr}$ at $1000^{\circ} \mathrm{C}$ ) 
of the product occurs at a mixing ratio of approximately $\mathbf{4 . 5}$ and coincides with a maximum content of vanadium. The same result is observed when sintered briquettes are reduced. Following a fusion treatment in the plasma-arc furnace, commercially available electrolytic, vanadium metal of $99.8 \%$ purity gives a Vickers hardness of $83^{2}$. This value is Indicated with a dotted line in Fig. 12. However, in this study, the minimum hardness value is 286 and this larger value. relative to pure vanadium, is attributed to the small quantities of carbon and oxygen in the product. When the mixing ratio is greater or less

2. Hv value of the vanadium metal of $99.8 \%$ purity (Its impurities are as follows: $\mathrm{C} 0.05 \%, \mathrm{O} 0.08 \%, \mathrm{~N}$ $0.04 \%, \mathrm{H} 0.008 \%$ ) is reported to be 93 . (Nippon Kinzoku Gakkai, Metals Databook, 147. (1974). than 4.5. the hardness of the product increases. Although the vanadium content is similar, when the mixing ratio is 4.25 and 4.75 . the hardness number of the former ratio is much lager. This is due to the fact that oxygen has a far greater effect than carbon on the product hardness /16/.

Fig. 13 shows the dependence of the Vickers hardness of the products on the reaction time. The product at zero reaction time is very hard because of the relatively large amounts of remaining oxygen and carbon. As the reduction advances, the hardness of the product decreases. When the reaction time exceeds 6 minutes, the hardness becomes constant and $\mathrm{H}_{\mathrm{V}}$ is approximately 300 . This result is in agreement with the abovementioned chemical analysis of the product.

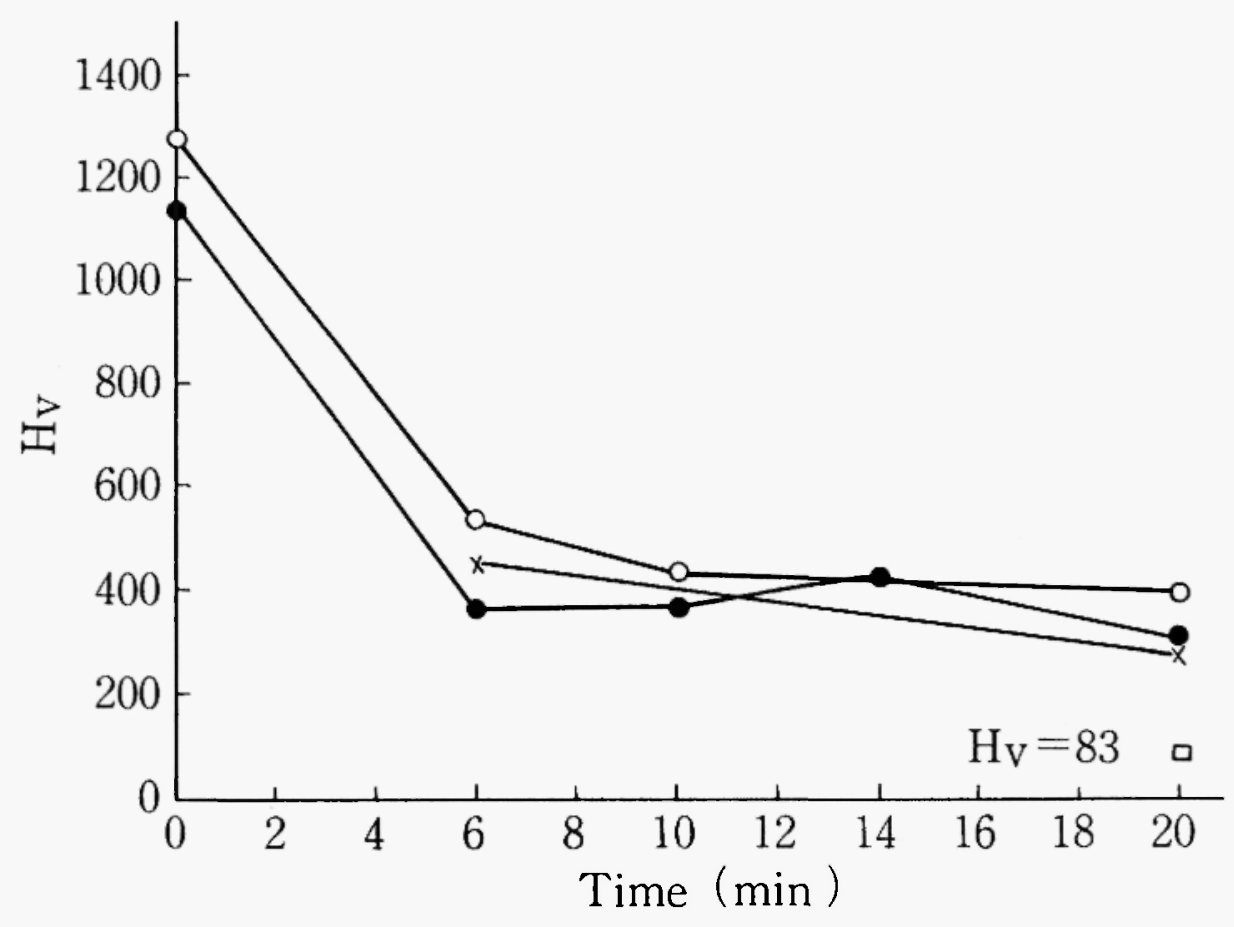

Fig. 13 Dependence of Vickers hardness of the products on the reaction time at $2100^{\circ} \mathrm{C}-\mathrm{o}-$ : not sintered $-\mathrm{x}-$ : sintered $1 \mathrm{hr}$ at $700^{\circ} \mathrm{C}, \ldots \ldots$ : sintered $1 \mathrm{hr}$ at $1000^{\circ} \mathrm{C}$ 


\section{B.1.6. Microscopic examination of the structure and a qualitative EPMA analysis}

The structure of the reduced briquettes with a mixing ratio of 4.5 is examined microscopically and the vanadium, carbon and oxygen contents qualitatively determined by means of EPMA. The samples are polished but not etched.

Photo 2 shows the microstructure of the sample with a reaction time of zero. In this

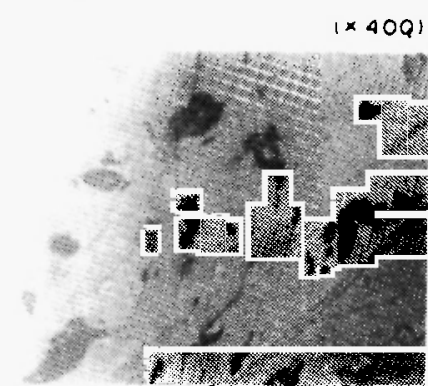

Photo. 2 Microstructure of the product $\left(\mathrm{C} / \mathrm{V}_{2} \mathrm{O}_{5} 4.5\right.$, not sintered, time $\mathrm{O}$ that is just after the melting down) Contents analyzed : V 86.1\%, C $4.8 \%$. O $7.1 \%$

micrograph, many black regions are observed, and it is difficult to determine whether these dark zones are newly formed carbide or remaining oxide phases. However, the hardness is greater than that of the surrounding structure. At this stage, the sample is still not uniformly reduced.

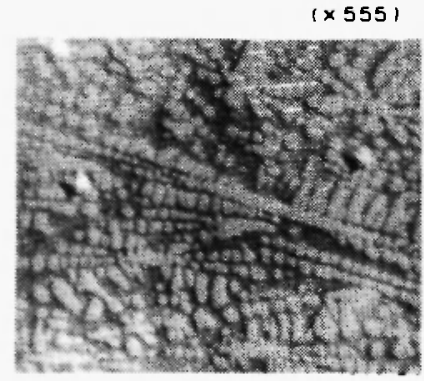

Photo. 3 Microstructure of the product $\left(\mathrm{C} / \mathrm{V}_{2} \mathrm{O}_{5} 4.5\right.$, not sintered, time 20 min.)

Contents analvzed : V 95.9\%, C 2.3\%. O $1.8 \%$
Photo. 3 shows the structure of the sample reduced for 20 minutes which contains about $96 \%$ vanadium. The dendritic crystals are distributed uniformly over the whole area. At a magnification of 1110 times, Photo. 4 and Photo. 5 show the microstructures of the products reduced for 6 and 20 minutes, respectively. While both show similar

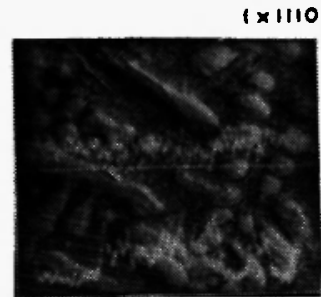

Photo. 4 Line scanning profles by EPMA for $\mathrm{V}$ and $\mathrm{C}\left(\mathrm{C} / \mathrm{V}_{2} \mathrm{O}_{5} 4.5\right.$, not sintered, time $6 \mathrm{~min}$.)

Contents analyzed : V 93.3\%, C 2.2\%. O 4.5\%

$\mathrm{V}-\mathrm{K} \propto(2 \mathrm{Kcps})$

$\mathrm{C}-\mathrm{K} \propto$. (500 cps)

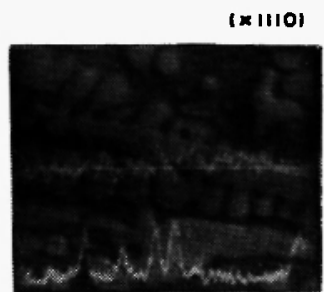

Photo. 5 Line scanning profles by EPMA for $\mathrm{V}$ and $\mathrm{C}$ of the sample shown on Photo. 3

$\mathrm{V}-\mathrm{K} \propto(2 \mathrm{Kcpts})$

$\mathrm{C}-\mathrm{K} \propto(200 \mathrm{cps})$

dendritic structures, the crystals of the latter are larger than the former. Therefore, a greater degree of reduction leads to the growth of larger dendrites.

To determine the distribution of vanadium. carbon and oxygen between the dendritic phase and the matrix, a qualitative analysis was performed by means of EPMA. The electron beam was scanned across the sample as indicated by the white. center line in each photograph at a velocity of $5 \mu \mathrm{m} / \mathrm{min}$. As shown by the analysis in Photo.. 4, the carbon content decreases in the 
dendritic phase while the vanadium content Increases. Conversely, the carbon content in the surrounding phase is relatively large. Similar behavior is observed in the analysis of a second sample, see Photo. 5. This latter sample is also analyzed for oxygen and the results are presented in Photo. 6. The oxygen is distributed almost uniformly between the two phases.

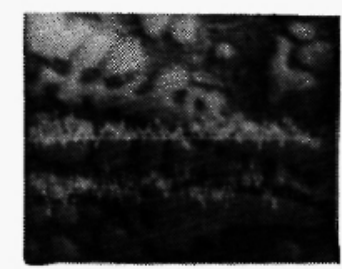

Photo. 6 Line scanning profles by EPMA for $\mathrm{V}$ and $O$ of the sample shown on Photo. 5 V-K (2 Kcps)

O-K (200 cps)

An explanation of the observed differences in the distribution of vanadium, carbon and oxygen between the two phases is presented with the aid of the vanadium carbon phase diagram by Storms et al. /17/ (Fig. 14) and the vanadium oxygen diagram by Alexander et al. /18/ (Fig. 15).

The reduction products containing less than a few percent of residual carbon lie on the vanadium-rich side of the $\mathrm{V}-\mathrm{V}_{2} \mathrm{C}$ eutectic. Therefore, during solidification, the sample will form a primary. dendritic phase of vanadium containing a small amount of carbon. The remaining liquid solidifies at the $\mathrm{V}-\mathrm{V}_{2} \mathrm{C}$ eutectic.

The oxygen solubility in the vanadium metal is $1.03 \%$ at room temperature, $2.14 \%$ at $510^{\circ} \mathrm{C}$ and approximately $6 \%$ at the peritectic reaction temperature of $1665^{\circ} \mathrm{C}$, see Fig. 15. Therefore, it is assumed that almost all the residual oxygen in the reduction product remains in solid solution, either in the primary dendritic or the eutectic phase.

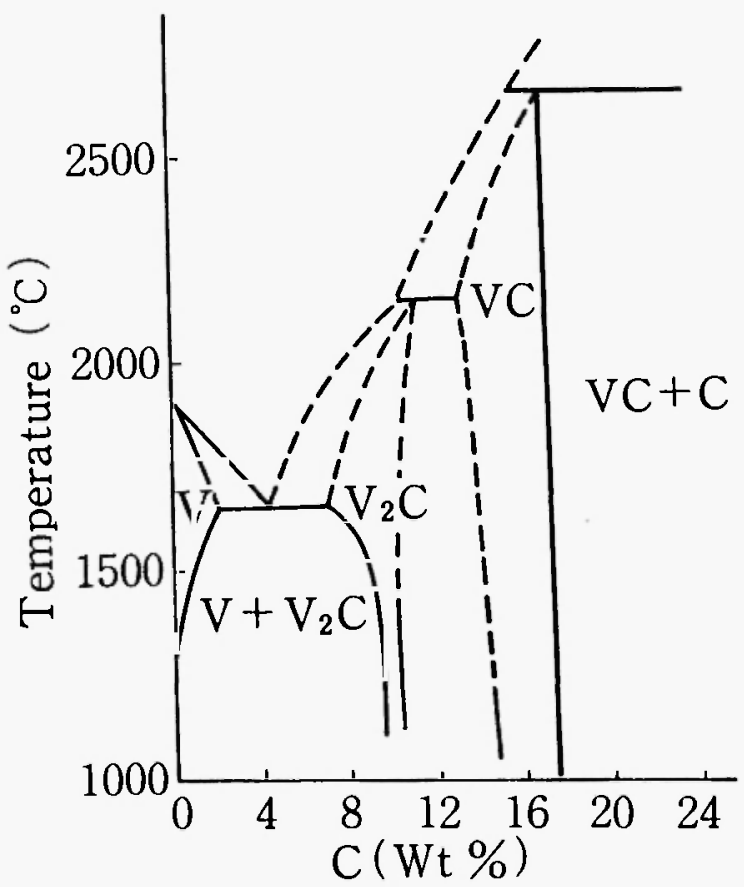

Fig. 14 Phase diagram of the V-C binary system (Storms et al. )

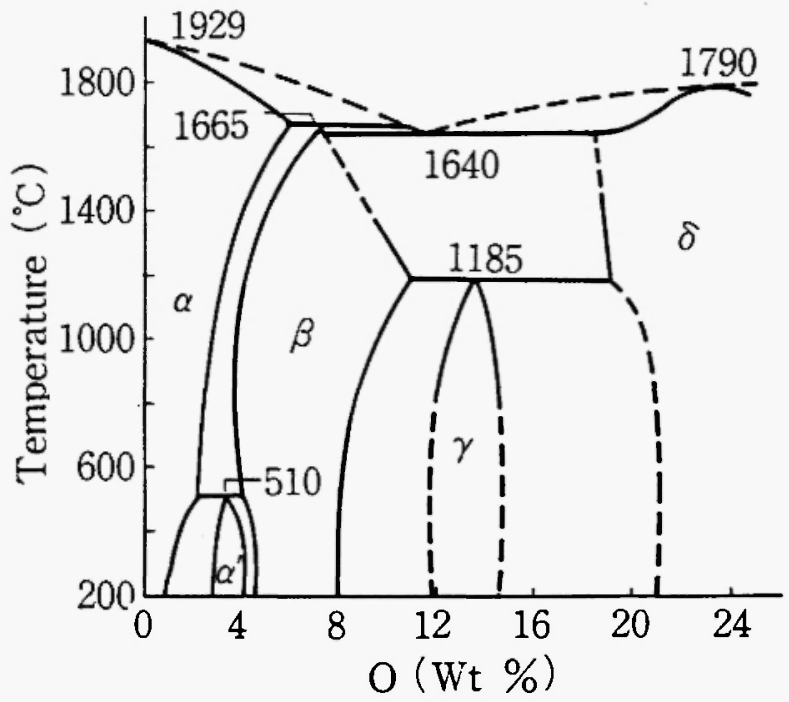

Fig. 15 Phase diagram of the V-O binary system (Alexander and Carlson)

B.2. 2nd Step Reduction Refining of the Crude Vanadium by $\mathrm{Ar}-\mathrm{H}_{2}$ plasma arc)

As mentioned above, the carbon reduction of 
vanadium pentoxide was carried out by argon plasma arc smelting. However, the product was crude vanadium which contained a small amount of carbon and oxygen, see Figs. 5 and 6.

In the second step, this crude vanadium metal was smelted by the $\mathrm{Ar}-\mathrm{H}_{2}(5 \sim 25$ vol. \%) plasma-arc furnace. The alm was the deoxidation and de-carburization of the crude metal and the production of high purity vanadium. In this case, the fundamental reactions are shown as follows:

(Carbon reduction)

$$
\mathrm{V}_{2} \mathrm{O}_{5}+5 \mathrm{C}=2 \mathrm{~V}+5 \mathrm{CO}
$$

$$
\underline{C_{-}}(\ln \mathrm{V})+\underline{\mathrm{O}_{-}}(\ln \mathrm{V})=\mathrm{CO}
$$

$$
\mathrm{VC}+\mathrm{VO}=2 \mathrm{~V}+\mathrm{CO}
$$

$$
\mathrm{K}_{6}=\frac{\mathrm{pco}}{\mathrm{a}_{\mathrm{C}} \cdot \mathrm{a}_{\underline{0}}}
$$

(Deoxidation with hydrogen)

$$
\underline{O}(\ln \mathrm{V})+2 \mathrm{H}=\mathrm{H}_{2} \mathrm{O}
$$

or

$\mathrm{VO}+\mathrm{H}_{2}=\mathrm{V}+\mathrm{H}_{2} \mathrm{O}$

$$
\mathrm{K}_{7}=\frac{\mathrm{pH}_{2} \mathrm{O}}{\mathrm{a}_{\mathrm{O}} \cdot \mathrm{p}^{2} \mathrm{H}}
$$

(Decarburization with hydrogen)

$$
\mathrm{xC}(\ln \mathrm{V})+\mathrm{yH}=\mathrm{CxHy}
$$

or $\mathrm{VC}+2 \mathrm{H}_{2}=\mathrm{V}+\mathrm{CH}_{4}$

$$
2 \mathrm{VC}+\mathrm{H}_{2}=2 \mathrm{~V}+\mathrm{C}_{2} \mathrm{H}_{2}
$$

$$
\mathrm{K}_{8}=\frac{\mathrm{pC}_{\mathrm{x}} \mathrm{H}_{\mathbf{y}}}{\mathrm{a}_{\mathrm{c}}^{\mathrm{x}} \cdot \mathrm{p}_{\mathrm{H}}^{\mathrm{y}}}
$$

$\mathrm{C}$ and $\mathrm{O}$ in these equations represent the dissolved contents of carbon and oxygen in crude vanadium melt.

Because temperature of the plasma-arc flame is very high, $10000 \sim 5000 \mathrm{~K}$, it is expected that the greater parts of hydrogen molecule dissociate into an atomic state ${ }^{3}$ and react in this state ${ }^{4}$.

Fig. 16 shows the changes in free energy with temperature calculated by thermodynamical data 113.19/. As for the carbon reduction of oxldes, the possibility of the reaction (6) or (6') is considered to be ultimately important. In the case of deoxidation and decarburization of molten crude vanadium, the equilibrlum constant of the mutual reaction of $\mathrm{C}$ and $\mathrm{O}$ is $\mathrm{K}_{6}$ with the reaction advancing slowly for a long time under high temperature and low pressure. This is deducted from the reports on the equilibrlum consideration by Chipman et al. /15/ and Makunin et al. /20/.

However, the affinities of $\mathrm{V}$ with $\mathrm{C}$ and $\mathrm{O}$ are large and the activities of $\mathrm{C}$ and $\mathrm{O}$ are considered to decrease with the decrease of the contents of $\mathrm{C}$ and $O$ in the vanadium metal. Then the elimination of small amounts of residual $\mathrm{C}$ and $\mathrm{O}$ will be still more difficult. As is seen clearly in Fig. 16. deoxidation with hydrogen at a high temperature (see equations (7) and (7')) is considered to accelerate with raising the partial pressure of the hydrogen surrounding the sample material and conversely with lowering the partial pressure of produced water vapor. In other words, if the ratio of $\mathrm{PH}_{2} \mathrm{O} / \mathrm{PH}_{2}$ is less than or equal to $10^{-3}$, the deoxidation advances.

3. At 1 atmosphere, $5000 \mathrm{~K}$, the dissociation degree of hydrogen molecule, $\alpha$, reaches about $96 \%$.

4. When the plasma-arc flame is blown on the surface of the sample material, it is expected that the temperature of the flame gas drops down and the dissociated hydrogen atoms reunite to make molecules. 


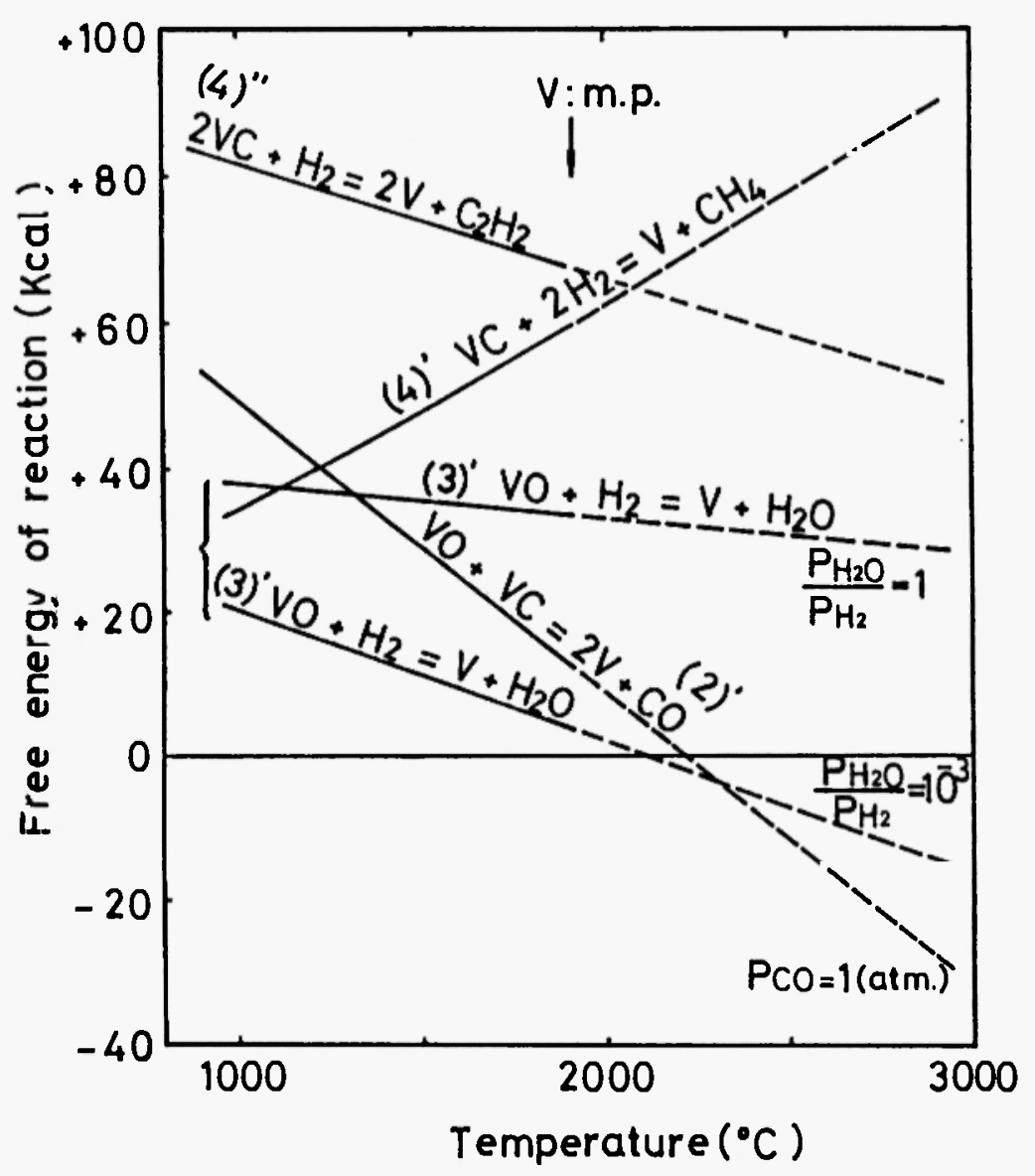

Fig. 16 Free energy changes of reaction for deoxidation and decarburization reactions of $\mathrm{V}$

In the case of this second step smelting, arc generating gas (mlxture of $\mathrm{Ar}$ and $\mathrm{H}_{2}$ ) is blown around the sample ceaselessly creating a stream. Th1s process agrees with the above-mentioned acceleration condition.

Furthermore, the vaporization of vanadium suboxide $\left(\mathrm{VO}_{\mathrm{X}}\right)$ is also considered to accelerate the deoxddation and is discussed later.

As a result of the decarburization reaction with hydrogen, several kinds of hydrocarbon are produced (see equation (8), etc.).

Fig. 16 shows the calculated free energy of $\mathrm{CH}_{4}$ and $\mathrm{C}_{2} \mathrm{H}_{2} \cdot{ }^{5}$ Based on these results, the effect of decarburization with hydrogen at high temperature is estimuted to be small as compared with the effect of deoxidation. By the way, the effect of atomic hydrogen is expected to be larger than that of the molecular state on the deoxidation and the decarburization, due to the lower value of the free energy of reaction at the atomic state, see equations (7) and (8).

\section{B.2.1. Experimental methods}

A briquette formed by mixing $\mathrm{V}_{2} \mathrm{O}_{5}$ and graphite (about $5 \mathrm{~g}, 15 \mathrm{~mm} \phi, 10 \mathrm{~mm} \mathrm{~h}$ ) was sintered for 1 hour at $1000^{\circ} \mathrm{C}$ in argon atmosphere as described in the preceding section. This 
briquette made of several mixing ratios, $\mathrm{C} / \mathrm{V}_{2} \mathrm{O}_{5}$. was reduced in $\mathrm{Ar}$ plasma-arc at $2100^{\circ} \mathrm{C}$ for 10 minutes. This product of crude vanadium was used as the sample for the second step smelting.

This crude metal was smelted in the Ar$\mathrm{H}_{2}(5,10,25$ vol.\%) plasma-arc flame at a temperature range of $2600^{\circ} \sim 2900^{\circ} \mathrm{C}$ and the deoxidation and the decarburzation of the metal were examined.

Sample metals are turned over every 5 minutes and the total minutes of this experiment are taken to be the reaction time of second step smelting. The power output of the plasma-arc furnace In this step is practically constant and about $7 \mathrm{KW}$. Arc voltage rises from 35 to $52 \mathrm{~V}^{6}$ and the current decreases from 192 to $140 \mathrm{~A}$ in proportion to the increase of hydrogen content of the operating gas from 0 to 25 vol. $\%$. When hydrogen content exceeds 30 vol. \%, the generation of the plasma-arc is difflcult due to the small output power of our furnace. Then hydrogen content of $\mathrm{Ar}-\mathrm{H}_{2}$ has used ranges from 5 to 25 vol.\%. Photo. 7 shows the sample materials $\left(\mathrm{C} / \mathrm{V}_{2} \mathrm{O}_{5}=4.05\right)$ at several stages as follows:

(A) An initial briquette

(B) A briquette, preliminary sintered (A) for $1 \mathrm{hr}$., at $1000^{\circ} \mathrm{C}$.

(C) A product obtained by the first step, its surface flat and having a somewhat sllver luster.

5. The following kinds are considered to exist in this case as hydrocarbon gas: $\mathrm{CH}, \mathrm{CH}_{2}, \mathrm{CH}_{3}, \mathrm{CH}_{4}, \mathrm{C}_{2} \mathrm{H}_{2}$, etc. However, when temperature is lower than $2000^{\circ} \mathrm{C}$, mainly $\mathrm{CH}_{4}$ exists and when temperature rises to about $3000^{\circ} \mathrm{C}, \mathrm{CH}$ and $\mathrm{C}_{2} \mathrm{H}_{2}$ are superior.

6. The rise in voltage is considered to be due to the increase in dissociation energy of the hydrogen molecule.

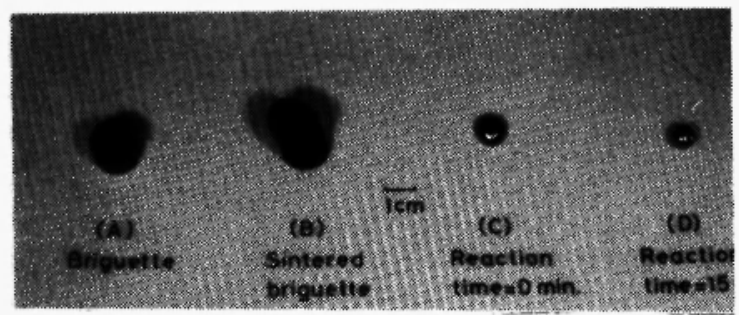

Photo. 7 Photographs of the sample materials before and after the plasma arc treatment $\left(\mathrm{C} / \mathrm{V}_{2} \mathrm{O}_{5}\right.$ : 4.05).

(A) A briquette,

(B) A briquette, sintered $1 \mathrm{hr}$. at $1000^{\circ} \mathrm{C}$

(C) A product obtained by lst-step

(D) A product obtained by 2nd-step. reaction time: $10 \mathrm{~min}$

(D) A product obtained by the second step, reaction time $10 \mathrm{~min}$. in $\mathrm{Ar}-\mathrm{H}_{2}$ (25 vol.\%) plasma-arc. This is roundish and has a better metallic luster

B.2.2. The residual carbon and oxygen contents of the 1st step carbothermic reduction in crude vanadium

As mentioned above, the crude vanadium was produced by carbothermlc reduction of vanadium pentoxide, and a second step sample was prepared.

In the second step smelting, residual carbon and oxygen contents in crude metal are an Important factor. As shown in Figs. 5 and 6, both contents in a crude metal were dependent and controlled by the mixing ratio, $\mathrm{C} / \mathrm{V}_{2} \mathrm{O}_{5}$. In other words, when the mixing ratio increases, carbon content increases and oxygen content decreases. In the case of the optimum mixing ratio of 4.5 , the maximum content attained is only 96 wt $\%$ vanadlum. Then in the second step smelting. we can adopt several kinds of first step crude vanadium which have varlable contents of carbon and oxygen and examine the effect of hydrogen 
contained in the arc-gas on the deoxddation and the decarburization.

\section{B.2.3. The effect of hydrogen on the deoxidation and the decarburization}

Fig. 17 shows the results of the second step reduction. The crude vanadium of the first step was smelted 10 minutes with $\mathrm{Ar}-\mathrm{H}_{2}$ (25 vol.\%) plasma-arc. This shows the effect of the initial $\mathrm{C} / \mathrm{V}_{2} \mathrm{O}_{5}$ on $\mathrm{V}, \mathrm{C}$ and $\mathrm{O}$ contents together with the Vickers hardness number, $H_{v}$. of the second step products.

A solld line shows the residual content of $O$ in $\mathrm{V}$ and this value decreases by the order of several wt.\% as compared with that of the first step products (shown in dotted line). On the contrary. the decrease of $\mathrm{C}$ content is insufficient. That is. the effect of hydrogen on the decarburization is small while the deoxidation effect is very great as described above.

As shown in Figs. 5, 6 and 17, the crude vanadium from the first step reduction at a mixing ratio of $4.00 \sim 4.10$ has only $94 \mathrm{wt} . \%$ of vanadium content, and much residual oxygen and a somewhat small quantity of carbon remains. Then, as the raw material of the second step smelting, these products are profitable because most of the oxygen is eliminated by hydrogen. The purity of the product reaches $99.6 \mathrm{wt} . \%$ of $\mathrm{V}$.

Fig. 18 shows the relation between $C$ and $O$ contents in both the first and second products. We see the shift to the lower content of $\mathrm{C}$ and $\mathrm{O}$ by the second step smelting.

As for the hardness, the minimum Hv of the first step products (dotted line) is about 290 $\left(\mathrm{C} / \mathrm{V}_{2} \mathrm{O}_{5}\right.$ of this : 4.50) while the value of the second step products (solid line) is about 180 (in the case of $\mathrm{C} / \mathrm{V}_{2} \mathrm{O}_{5}: 4.10$ ), see Fig. 17 , and this problem will be discussed later.

Furthermore, X-ray diffraction of the second step products was examined. As shown In Figs. 10 and 11 , the main peaks of the first step products are those of $\mathrm{V}$ and $\mathrm{V}_{2} \mathrm{C}$. In the case of the second step products, however, peaks of $\mathrm{V}$ are only obtained for samples of $\mathrm{C} / \mathrm{V}_{2} \mathrm{O}_{5} 4.00 \sim 4.10$ due to the good purity of the products. This result agrees well with the chemical analysis of the product metals.

Table 2 shows the typical analysis of vanadium metal produced by second step smelting 7 . Overall $\mathrm{V}$ metal yields of first and second step smelting are typically above $85 \%^{8}$.

\section{TABLE 2}

Typical analysis of vanadium produced in present work [reaction conditions] INITIAL $\mathrm{C} / \mathrm{V}_{2} \mathrm{O}_{5}: \quad: \quad 4.00 \sim 4.10$ PLASMA GAS : : Ar- $\mathrm{H}_{2} .25 \mathrm{vol} \%$ REACTION TIME : $10 \mathrm{~min}$.

\begin{tabular}{|c|c|c|c|}
\hline Element & Weight \% & Element & Weight $\%$ \\
\hline $\mathbf{V}$ & $\approx 99.6$ & $\mathrm{Fe}$ & $<0.001$ \\
\hline C & $0.1-0.4$ & $\mathbf{M g}$ & $<0.001$ \\
\hline 0 & $0.4 \sim 0.02$ & $\mathrm{Na}$ & $<0.001$ \\
\hline $\mathrm{H}$ & $0.005 \sim 0.015$ & $\mathrm{Ti}$ & ND \\
\hline $\mathrm{Zn}$ & $<0.002$ & $\mathrm{Cr}$ & ND \\
\hline $\mathrm{Cu}$ & $<0.002$ & Mo & ND \\
\hline Mn & $<0.002$ & Si & - \\
\hline
\end{tabular}

ND : not detected

7. The impurities in metal products were analyzed by emission spectrochemical analysis and atomic absorption spectrometry, semi quantitatively.

8. Metal yields were calculated from the amount of vanadium contained in the briquette of the first step smelting. 


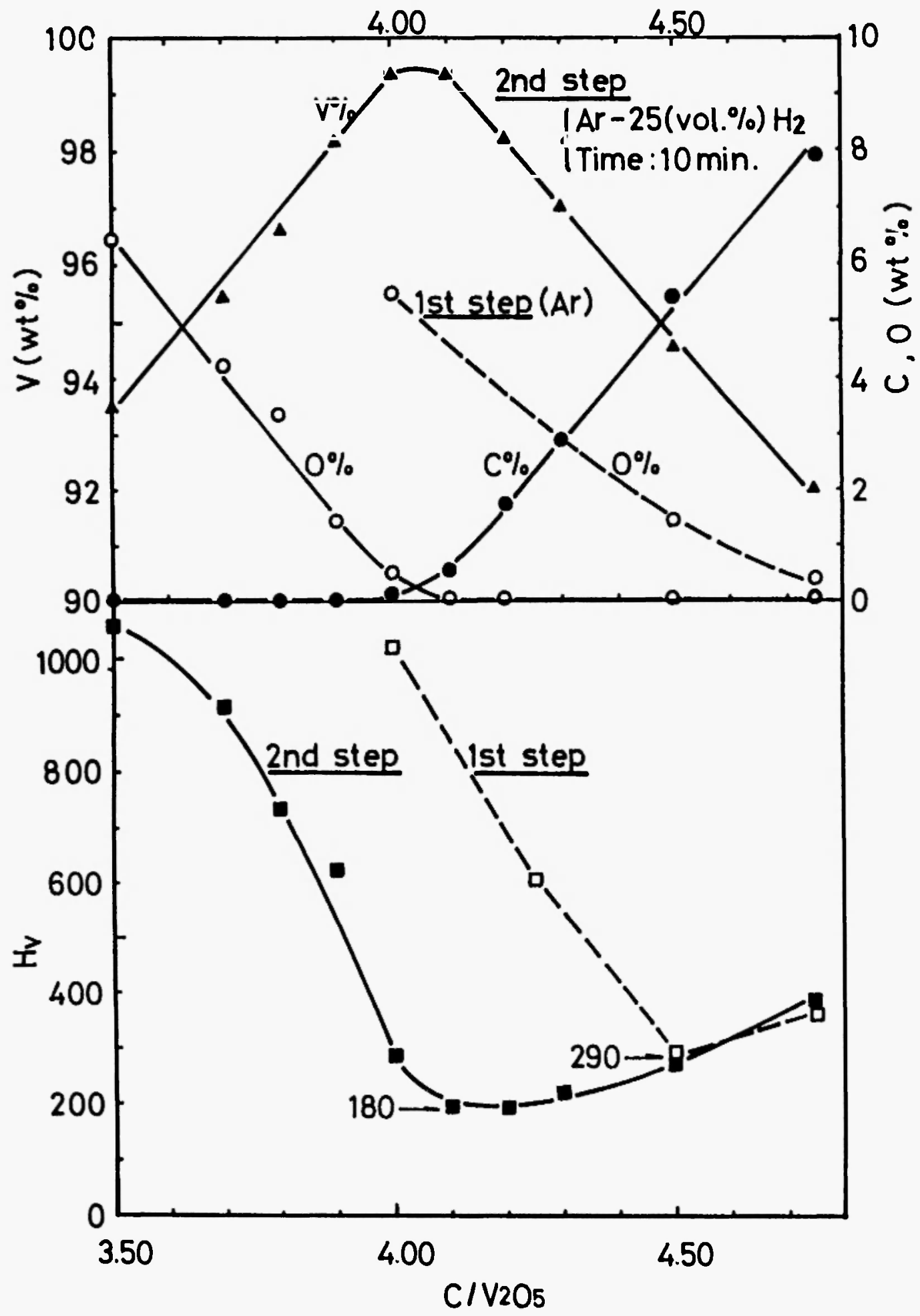

Fig. 17 Dependence of $\mathrm{V}, \mathrm{C}, \mathrm{O}$ contents and Vickers harness number of the products on $\mathrm{C} / \mathrm{V}_{2} \mathrm{O}_{5}$ 


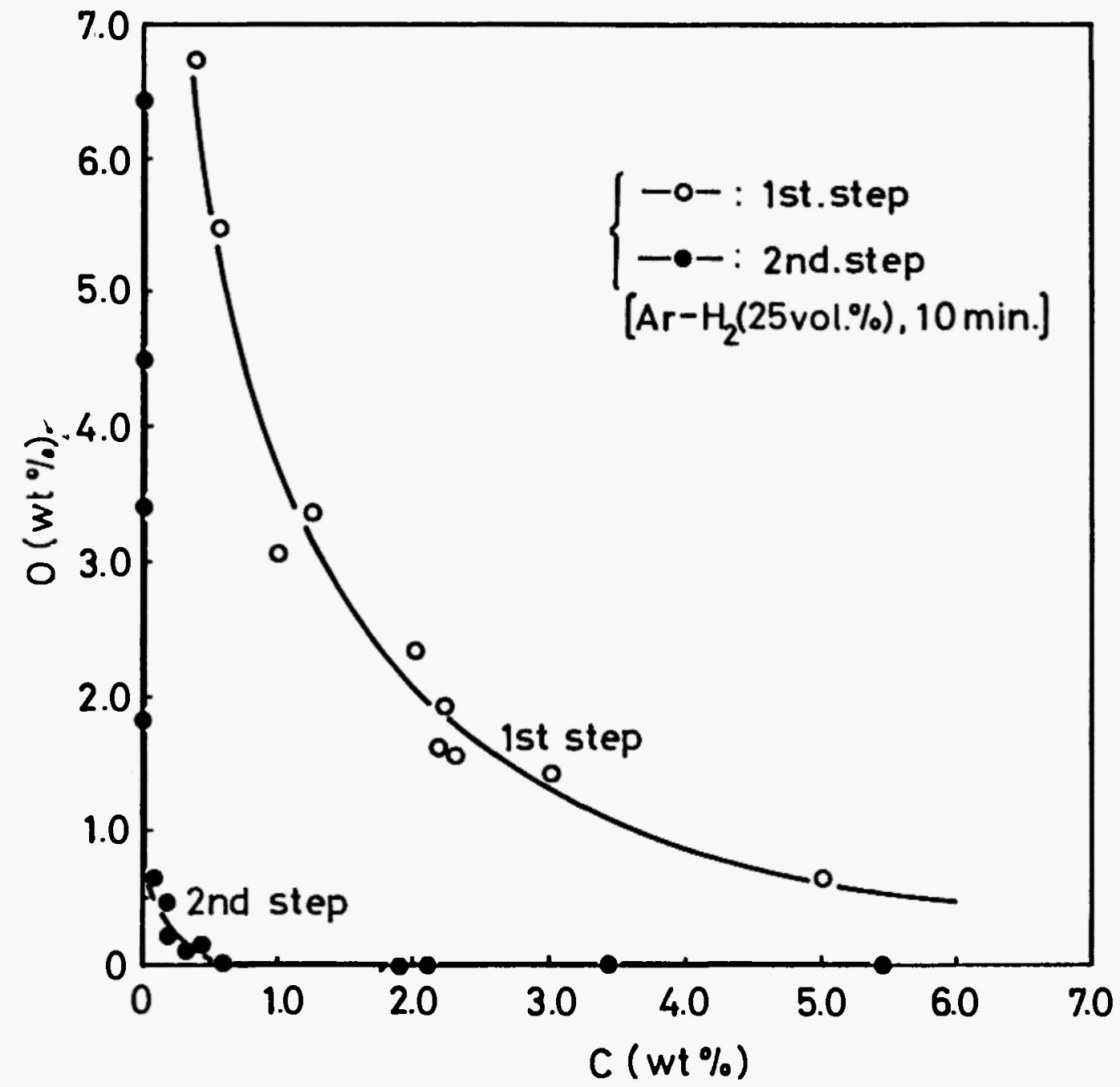

Fig. 18 Relation between Carbon and Oxygen contents of the products

\section{B.2.4. The effect of reaction time}

Fig. 19 shows the effect of reaction time on $V$. $C$ and $O$ contents together with the Vlckers hardness number of the products. In this case, the mixing ratio of the first step sample is 4.10 and crude vanadium contains $3 \sim 4 \mathrm{wt}$. $\%$ of $O$. In the second step smelting, $\mathrm{Ar}-\mathrm{H}_{2}$ (25 Vol.\%) plasmaarc was used.
Remarkable deoxidation occurred at the early stage of the reaction. and oxygen content reaches 0.02 wt.\% after 10 minutes. On the contrary. decarburization is insufficient as compared with the decrease of oxygen content and carbon content remains about 0.4 wt.\% after 10 minutes reaction. Vanadium content of this second step product reaches $99.6 \mathrm{wt} \%$ and the value of the $\mathrm{H}_{\mathrm{V}}$ also decreases remarkably. These effects are 


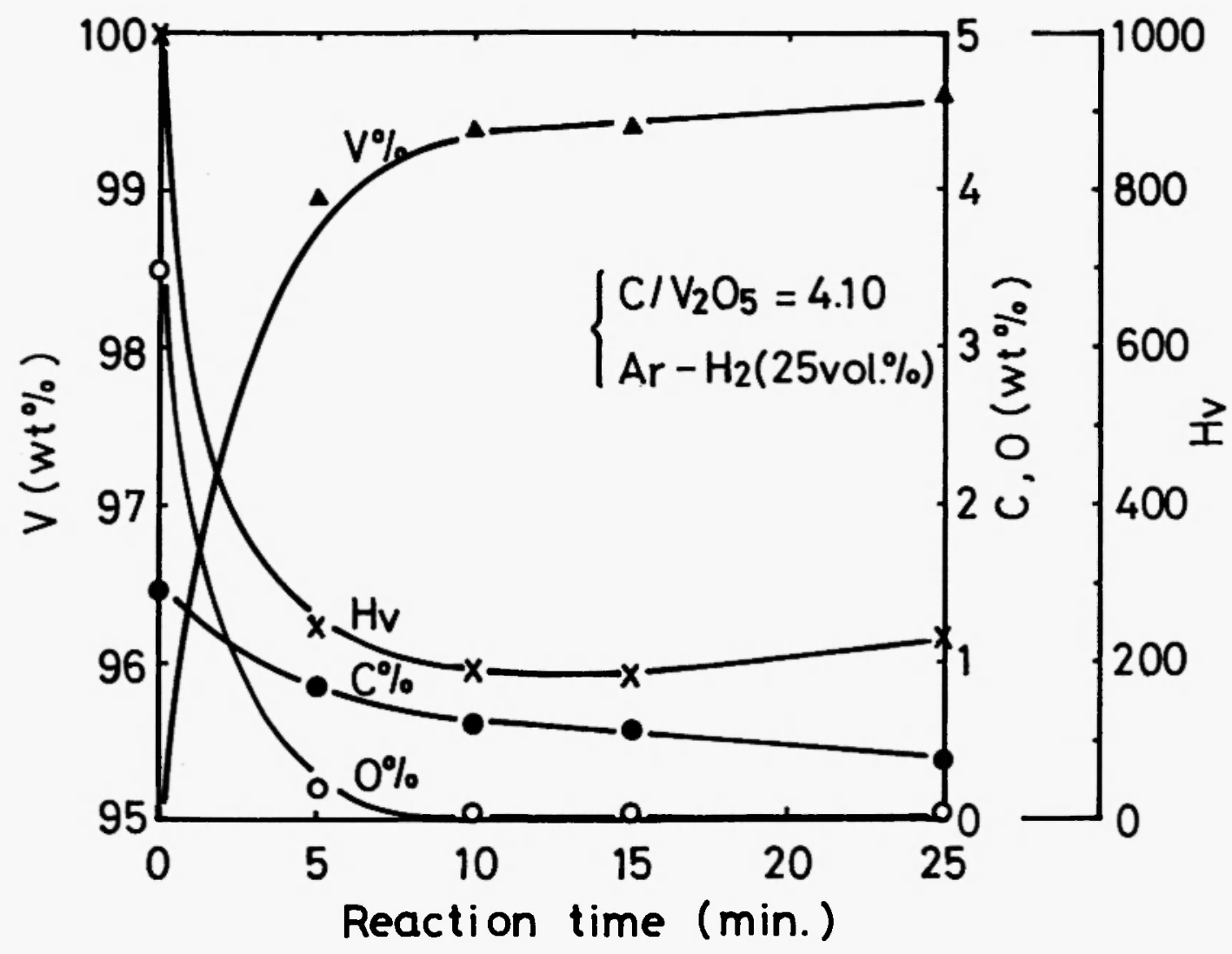

Fig. 19 Dependence of V. C, O contents and Vickers hardness number of the products on the reaction time

mainly the result of the advance deoxidation.

\section{B.2.5. The effect of hydrogen in plasma-arc generating gas}

Fig. 20 shows the effect of plasma arc generating gas (vol.\% $\mathrm{H}_{2}$ in $\mathrm{Ar}$ ) on $\mathrm{V}, \mathrm{C}$ and $\mathrm{O}$ contents together with $\mathrm{H}_{V}$ of the second step products. Contents of $\mathrm{H}_{2}$ added In arc gas are 0,5 , 10 and 25 vol.\%. Here first step products are the same as mentioned above $\left(\mathrm{C} / \mathrm{V}_{2} \mathrm{O}_{5}=4.10\right.$, reaction time $=10 \mathrm{~min}$.). In the second step, these products (crude $\mathrm{V}$ metal) are smelted anew for 10 minutes by
Ar- $\mathrm{H}_{2}$ plasma-arc. The residual content of oxygen decreases with the increase of $\mathrm{H}_{2}$ in the arc generating gas. Even if the hydrogen content is as small as 5 vol.\%, the decrease of oxygen is relatively large as compared with the second product by the use of pure Ar gas (Vertical axis in Fig. 20 shows the result of pure Ar). The minimum content of oxygen reaches below 0.1 wt.\%. Fig. 21 shows the relation between carbon and oxygen contents in the second step products. In this figure, the area of small contents of Fig. 18 is magnified. As mentioned above, the addition of 


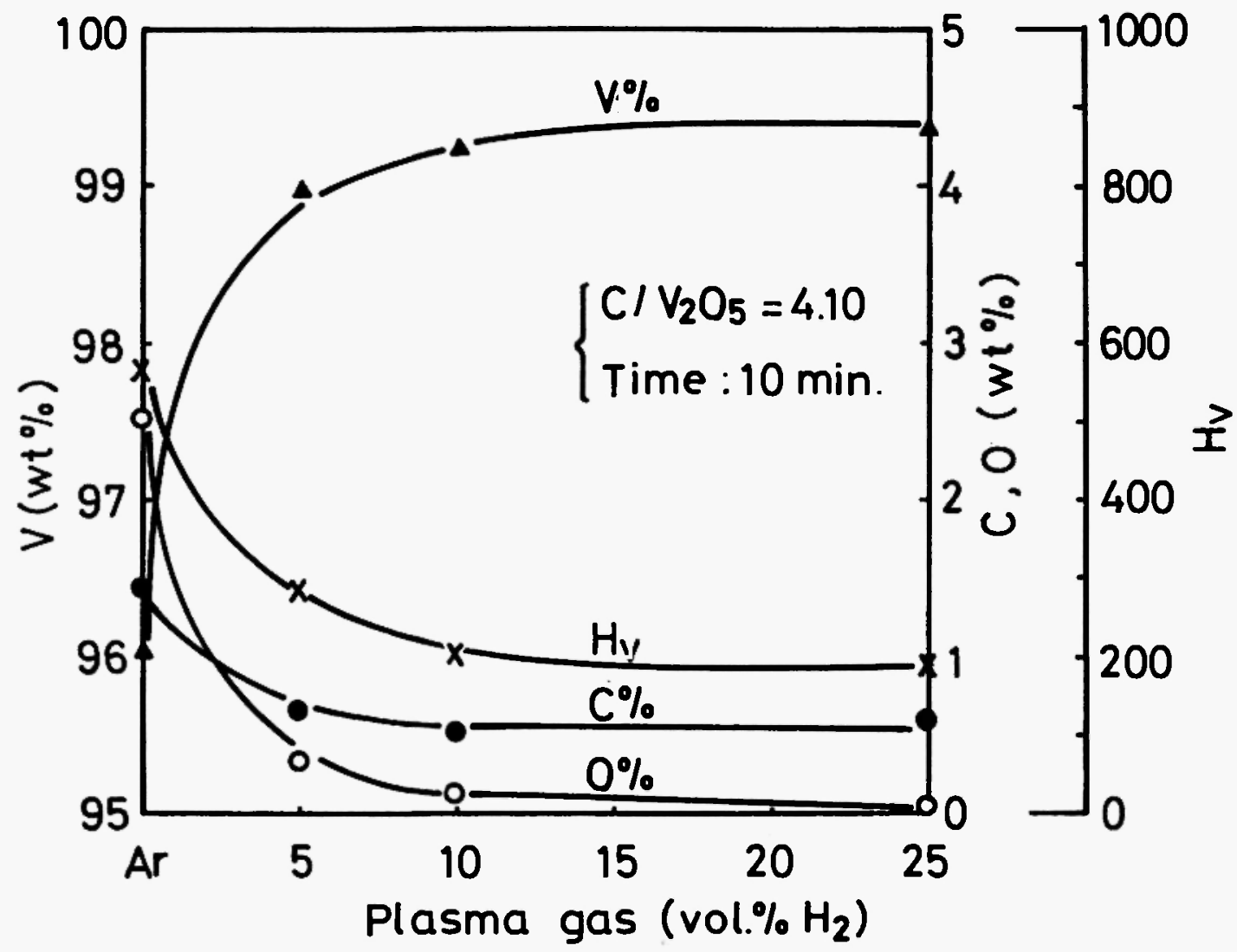

Fig. 20 Dependence of V, C, O contents and Vickers hardness number of the products on plasma gas $\left(\% \mathrm{H}_{2}\right)$

hydrogen in are generating gas shifts the $\mathrm{C}-\mathrm{O}$ curve of the second products to less residual contents and the effect of deoxidation is remarkable.

\section{B.2.6. Dependence of hardness of the products on restdual carbon and oxygen}

The hardness of metal is one of the indices of its mechanical properties. In general, the residual $C$ and $O$ contents of metal correspond well with hardness. Fig. 22 shows the dependence of Vickers hardness number, $\mathrm{H}_{\mathbf{v}}$ of the products on carbon and oxygen content. The black points and white points show the relation of $\mathrm{C}$ and $\mathrm{H}_{\mathrm{V}}$, and the relation of $\mathrm{O}$ and $\mathrm{H}_{\mathrm{V}}$, respectively ${ }^{9}$. The effect of carbon content is not so large and $\mathrm{H}_{\mathrm{V}}$ increases with the increase of carbon content slowly, as reported by Thompson et al. /21/. On the contrary, the effect of axygen content is very large and a

9. As for the second step products containing less than $0.05 \%$ of residual $\mathrm{C}$ or $\mathrm{O}$, respectively, we estimated that the dependence of hardness on the content of $\mathrm{O}(\mathrm{C}<$ $0.05 \%)$ or $\mathrm{C}(\mathrm{O}<0.05 \%)$ statistically. The correlation between $\mathrm{Hv}$ and $\mathrm{C}$ or $\mathrm{O}$ are perceived as shown in Fig., 22. 


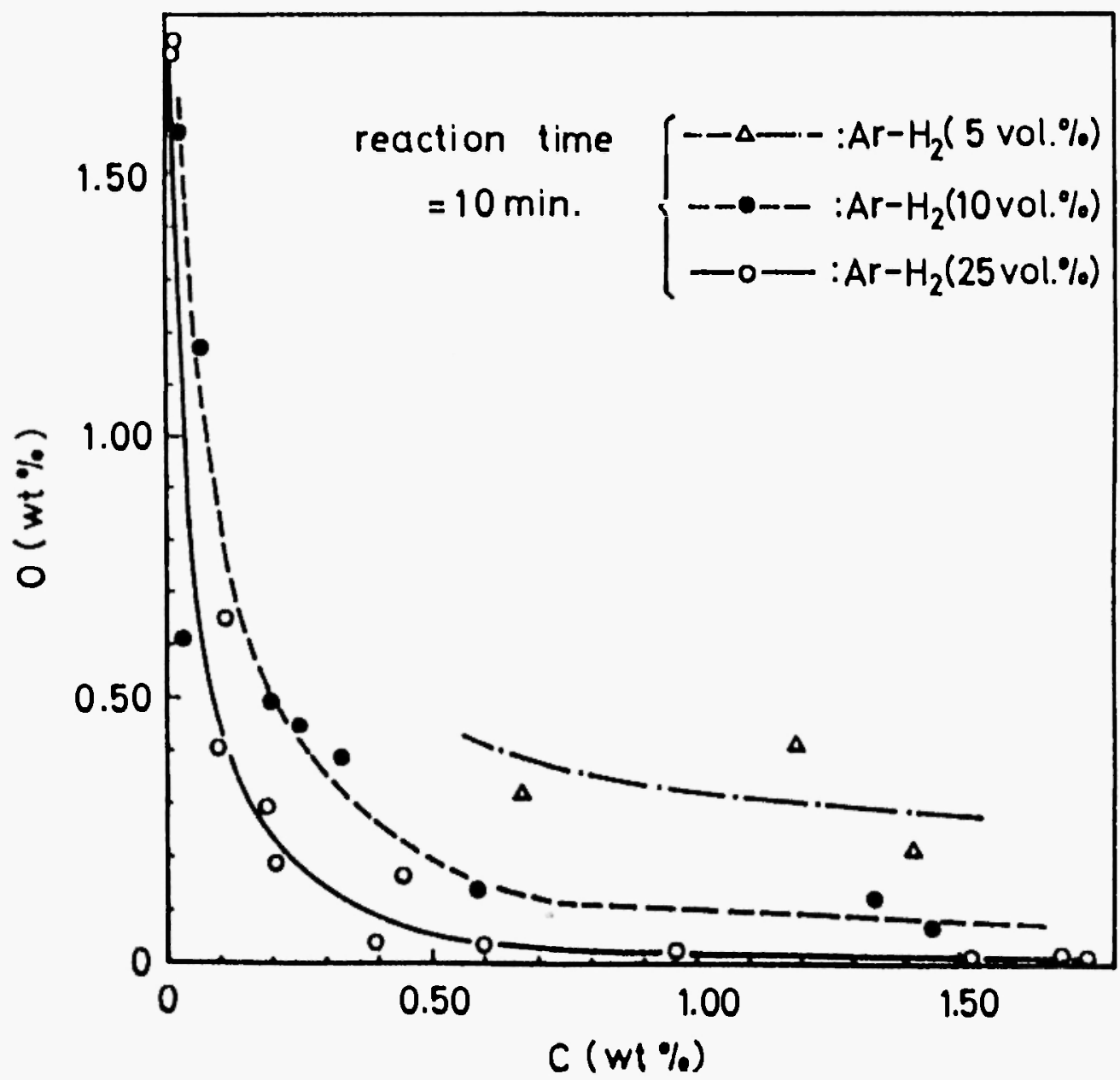

Fig. 21 Relation between carbon and oxygen contents in the products obtained by second step

remarkably. The results of Rostker et al. /22/ and Seybolt et al. /23/ are shown by broken lines in Fig. 22. These agree well with our results.

As for the vanadium metal in which the impurities were eliminated and refined through thermal decomposition or electro refining, a purity of over $99.9 \%$ and a value of less than 100 of $\mathrm{H}_{\mathrm{V}}$ are reported. Compared with these vanadium metals, the $H_{V}$ of our products is larger $\left(H_{V}=180\right)$ due to small amounts of residual $\mathrm{C}$ and $\mathrm{O}$. But our minimum $\mathrm{H}_{\mathrm{V}}$ is the same value of vanadium metal (>99.5\% V) as reported by McKechnie et al. /7/. They used reduction with $\mathrm{Ca}$.
As mentioned above, this $\mathrm{Ar}-\mathrm{H}_{2}$ plasma-arc refining of crude vanadium is considered to be very useful.

B.2.7. Consideration on the deoxidation reaction

Oxygen contained in vanadium reacts with hydrogen at high temperature and is eliminated mainly by the formation of water vapor. In this study the gas product formed by the reaction in the plasma-arc furnace is not analyzed chemically. Therefore, it is necessary to consider deoxidation by the formation of vanadium suboxides and their 


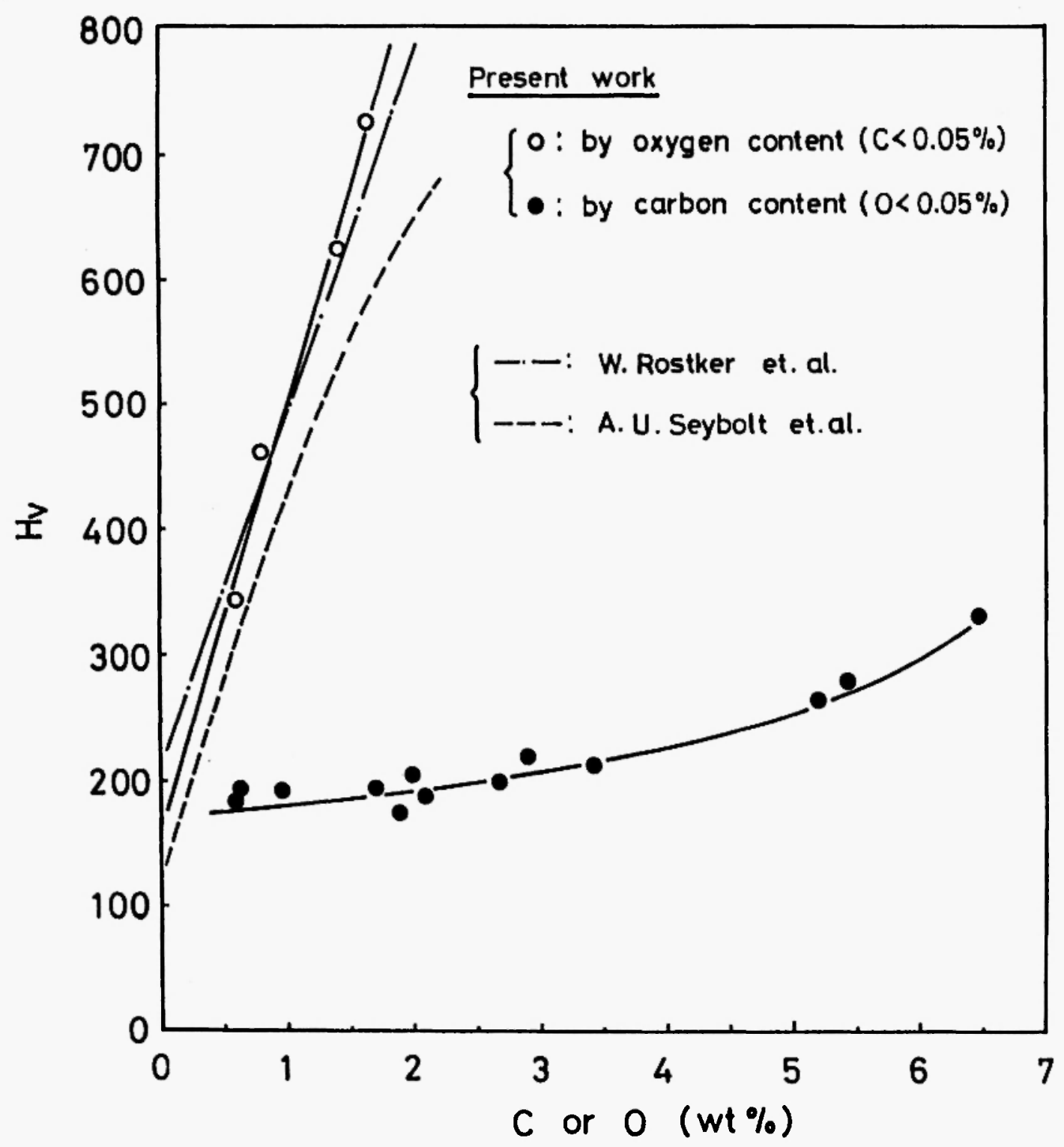

Fig. 22 Dependence of Vickers hardness number of the products on carbon or oxygen content

vaporization mentioned above.

Ono et al. /24/ reported the refining of $\mathrm{Nb}$ which is the same group metal as V. Niobium oxides were reduced with $\mathrm{C}$ and crude $\mathrm{Nb}$ containing small amounts of $\mathrm{C}$ and $\mathrm{O}$ were produced at first. Furthermore, through electron beam melting 10 , the low grade nioblum oxides (such as $\mathrm{NbO}, \mathrm{NbO}_{2}$ ) contained in crude $\mathrm{Nb}$ were vaporized producing pure $\mathrm{Nb}$.

10. Degree of vacuum : $10^{-4} \sim 10^{-5}$ tor 
Brewer et al. /25/ Investigated the vaporization and deoxidation of metal oxides from the viewpoint of equilibrium. They calculated the following value for ratio $R$ :

$$
R=\frac{(O / M) \text { vapor }}{(O / M) \text { metal }}
$$

where, $(\mathrm{O} / \mathrm{M})$ vapor equals the mol ratio between the contents of oxygen and metal in gas phase. $(\mathrm{O} / \mathrm{M})$ metal equals the same mol ratio in metal phase. They concluded that the possibility of deoxldation by vaporization of oxides is expected by value $R$. That is,

$$
\begin{array}{ll}
R \geq 10^{3}: & \text { the possibility is great } \\
R \geq 1: & \text { the possibility is small and } \\
& \text { vaporization loss of metal is } \\
& \text { large }
\end{array}
$$

The $\mathrm{R}$ of $\mathrm{Nb}$ and $\mathrm{V}$ at the melting temperature are calculated to be $10^{3}$ and 1 , respectively. Then, it is expected that deoxidation by vaporization of low grade oxides is effective for $\mathrm{Nb}$, but insufficient for $\mathrm{V}$, and vaporization loss in $\mathrm{V}$ metal is large.

Wang et al. /26/ reduced $\mathrm{V}_{2} \mathrm{O}_{5}$ with $\mathrm{Al}$ metal and produced crude $\mathrm{V}$ which contained about 10 wt.\% Al. This crude V was treated by electron beam melting to eliminate residual $A l$ and also to deoxidize with $\mathrm{Al}^{1} \mathbf{l}$. The maximum yleld of $\mathrm{V}$ metal is small, $70 \%$, and the vaporization loss of metal is considered to be great.

We considered the effect of low grade oxide $\left(\mathrm{VO}_{\mathrm{x}}\right)$ on deoxidation in our investigation. Flg. 23 shows the effect of reaction time on the weight loss of the products in the second step smelting.

11 It has been reported that aluminium content in crude $\mathrm{V}$ is about $10 \mathrm{wt} \%$, deoxidation is remarkable but the elimination of $\mathrm{C}$ and $\mathrm{N}$ (nitrogen) is difficult.
Weight loss is calculated using following equation:

Weight loss $=\left[1-\frac{\text { Sample weight }(\text { time }=t)}{\text { Sample weight }(\text { time }=0)}\right] \times 100 \%$

The broken lines show the results of the products treated by the arc-gas of $\mathrm{Ar}-\mathrm{H}_{2}$ (25 vol.\%), and the solid lines show those of pure Ar arc-gas. The numbers attached to each line are the mixing ratio, $\mathrm{C} / \mathrm{V}_{2} \mathrm{O}_{5}$, on the first step reduction.

For the crude vanadium containing much residual $\mathrm{O}\left(\mathrm{C} / \mathrm{V}_{2} \mathrm{O}_{5}\right.$ 4.10), weight loss of the products is very large with the use of $\mathrm{Ar}-\mathrm{H}_{2}$ (25 vol.\%) arc gas as compared with that of pure Ar gas. The weight loss proceeds rapidly at the early stage of the reduction by quick deoxidation, see Figs. 19 and 23. At the reaction time of 10 minutes, the amount of deoxldation is about $3.5 \mathrm{wt}$.\% and the weight loss of the sample is about $7.0 \mathrm{wt} . \%$.

By using this decreased oxygen amount, weight loss is calculated as follows: If $O$ in metal is eliminated by reaction with hydrogen and vaporization loss of metal does not occur, weight loss is about $4 \mathrm{wt}$ \%. If $\mathrm{O}$ forms low grade oxides such as VO and elimination of $O$ occurs totally through vaporization of this oxide, the weight loss of the products is calculated as about $15 \mathrm{wt} \%$.

Based on the above-mentioned calculation and the investigation results, deoxidation is considered to be advanced with the reaction of oxygen and hydrogen mainly. Then, the effect of oxygen elimination by the vaporization of oxides is small and good yields of vanadium metal are expected.

On the contrary, when first step products which contain a small amount of $O$ (such as the sample of mixing ration 4.50 ) is treated or the arc- 


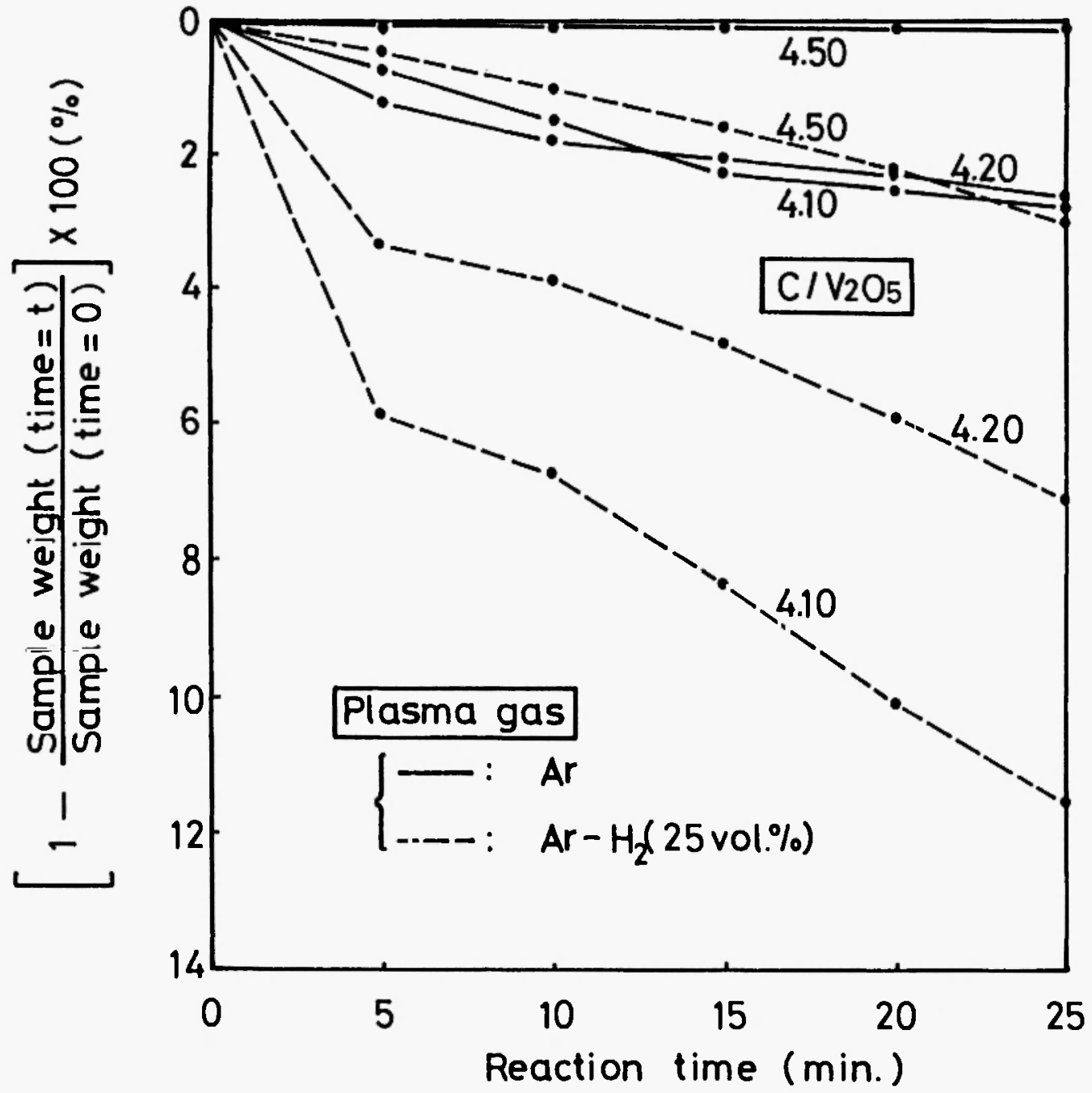

Fig. 23 Effect of reaction time on weight loss of the second step products

gas is pure Ar, the deoxidation amount and the weight loss are relatively small, see Fig. 23.

When the reaction is prolonged, however. the vaporization of vanadium metal has a tendency to increase and the yields of the metal decrease. Further investigation is necessary.

\section{ARC-PLASMA REDUCTION OF TANTALUM OXIDE WITH CARBON}

Metallic tantalum is one of the prominent refractory and corrosion-resistant metals. In the conventional production of tantalum, potassium tantalum fluoride $\left(\mathrm{K}_{2} \mathrm{TaF}_{7}\right)$ is reduced by heating with metallic sodium $/ 27,28 /$, and a metal powder Is produced.

As for the reduction of tantalum pentoxide, $\mathrm{Ta}_{2} \mathrm{O}_{5}$. by carbon or tantalum carbide, TaC. several experimental results were reported following the earliest report by Moissan et a. /2830/. Fig. 24 shows the Elligham diagram of Ta-C-O system calculated thermodynamically by Chipman et al. /15/. Based on this result, metallic 


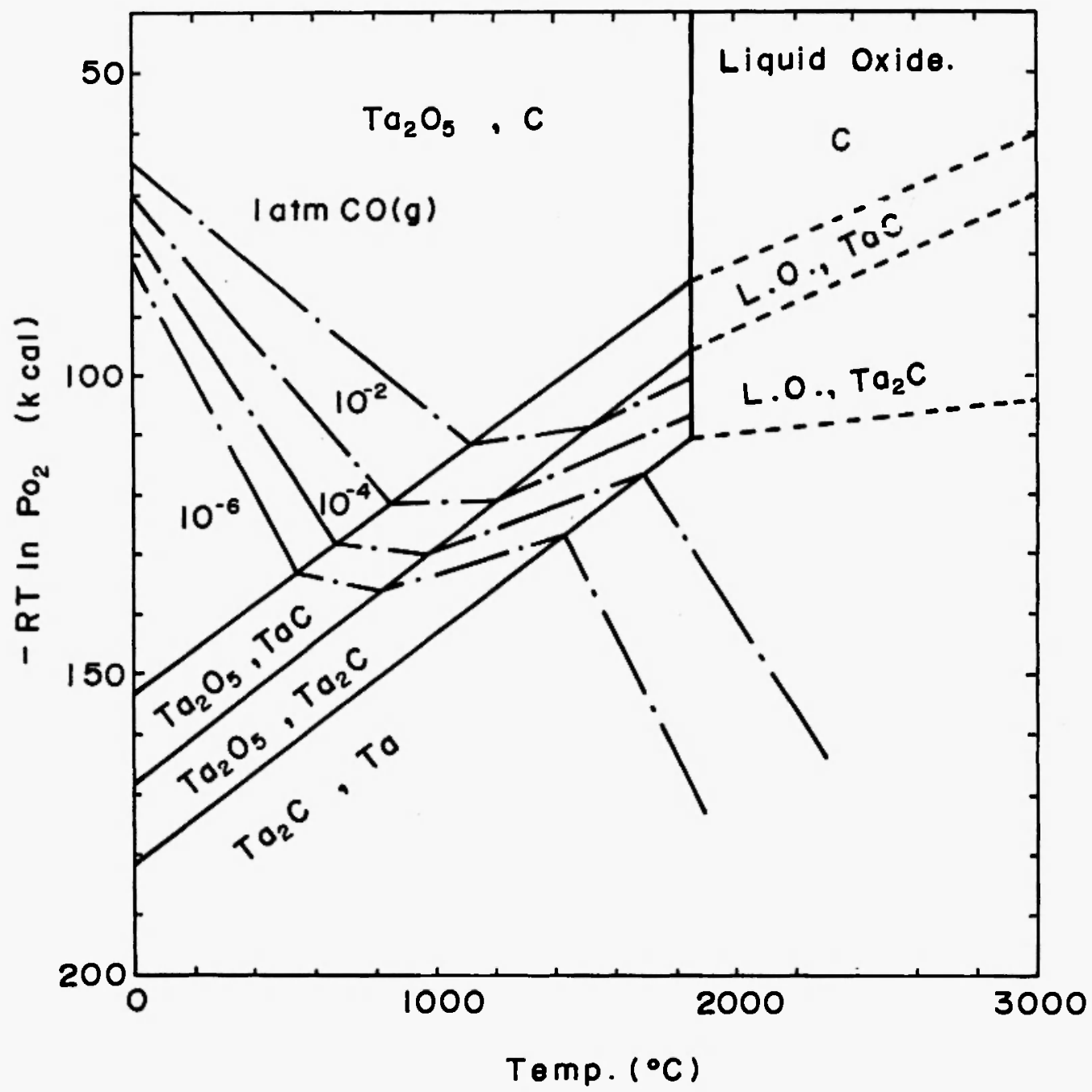

Fig. 24 Pourbalx Ellingham diagram for the Ta-C-O system (Worrell and Chipman)

tantalum can be produced through the prolonged carbon reduction of tantalum oxide at a temperature above $2000^{\circ} \mathrm{C}$ and under an evacuated state in which $\mathrm{P}_{\mathrm{co}}$ is about $10^{-4}$ torr. In the temperature range below the melting point of tantalum. $2990^{\circ} \mathrm{C}$, however, the reduction of oxide occurs slowly in the solid state and much carbon or oxygen remains in the reduction products. Therefore, long times and a high vacuum are necessary for this reaction below $3000^{\circ} \mathrm{C}$ and it is difficult to produce high purity metal by this method. In this work, we used an argon plasmaarc furnace, a technique used for the carbon reduction of vanadium pentoxide.

The sample oxide was reduced at about $3100^{\circ} \mathrm{C}$. The elimination reaction of oxygen and carbon proceeds rapidly in the molten state. Then. high purity massive tantalum which contains little carbon or oxygen is produced after a short reaction time. 


\section{A Experimental Methods}

The tantalum oxide used is powdered pentoxide with a particle size of minus 200 mesh and its purity is above $99.8 \%$. The reducing reagent is graphite powder of minus 300 mesh article size and its ash content is under $0.05 \%$. The major impurities in $\mathrm{Ta}_{2} \mathrm{O}_{5}$ are $\mathrm{Ca}, \mathrm{Si}, \mathrm{Mg}$, Fe and $\mathrm{Nb}$. Table 3 shows the spectrographic analysis of this tantalum pentoxide and the reduction product of tantalum metal. Selected ratios of the two materials are mixed for about 2 hours. These mixtures are vacuum briquetted under a pressure of 6 ton $/ \mathrm{cm}^{2}$. Each briquette is about $15 \mathrm{~mm}$ diameter and about $8 \sim 9$ in thickness and weighs $7 \mathrm{~g}$.

TABLE 3

Spectrographlc analysis of $\mathrm{Ta}_{2} \mathrm{O}_{5}$ and reduced tantalum metal impurities, ppm

\begin{tabular}{|l|c|c|c|c|c|c|}
\hline & $\mathrm{Ca}$ & $\mathrm{Si}$ & $\mathrm{Mg}$ & $\mathrm{Fe}$ & $\mathrm{Cu}$ & $\mathrm{Nb}$ \\
\hline $\mathrm{Ta}_{2} \mathrm{O}_{5}$ & $100-200$ & $10-100$ & $10-100$ & $10-100$ & $1-10$ & $<30$ \\
$\mathrm{Ta}$ & $<10$ & $<10$ & $<10$ & $<10$ & $\mathrm{ND}$ & $<30$ \\
\hline
\end{tabular}

ND : not detected

The fundamental reaction of reduction is shown as follows:

$$
\mathrm{Ta}_{2} \mathrm{O}_{5}+5 \mathrm{C}=2 \mathrm{Ta}+5 \mathrm{CO}
$$

Then, the stoichlometric mixing ratio of carbon to tantalum pentoxdde, $\mathrm{C} / \mathrm{Ta}_{2} \mathrm{O}_{5}$, is 5 . However, to find the optimum mixing ratio. the reduction of briquettes with the mixing ratios of 4.50 to $\mathbf{5 . 5 0}$ was studied. To prevent sample material from scattering during plasma-arc heating. the briquette is sintered at $1000^{\circ} \mathrm{C}$ for 1 hour in an argon atmosphere prior to the reduction.

The time spent to melt the preliminary sintered briquette is approximately $60 \sim 70$ seconds. It should be noted that in this work the instant when the briquette is fused and forms a liquid button, is considered to be the starting time of the reaction. After this time, the reaction is continued for a given number of minutes, the sample material is turned over, and the reaction is continued for an equal time interval. Total time of both heat treatments is taken to be the reaction time.

The remaining carbon and oxygen of the reduction products are analyzed by the method of coulometric determination. Other impurities are analyzed by the emission spectrochemical analysis. Furthermore, X-ray diffraction analysis, Vickers hardness measurements, microscopic observations, and EPMA analysis for the reduction products were carried out. 
B. Results and Discussions

B.1. The effect of the mixing ratio, $\mathrm{C} / \mathrm{Ta}_{2} \mathrm{O}_{5}$

Tantalum has a strong affinity for carbon and oxygen. To find the most suitable reducing condition, the mixing ratio, $\mathrm{C} / \mathrm{Ta}_{2} \mathrm{O}_{5}$, in the briquette was varied from 4.50 to $\mathbf{5 . 5 0}$.

Fig. 25 shows the dependence of tantalum. carbon and oxygen contents of the reduction products on the ratio, $\mathrm{C} / \mathrm{Ta}_{2} \mathrm{O}_{5}$ at a reaction temperature of about $3100^{\circ} \mathrm{C}$ and a reaction time

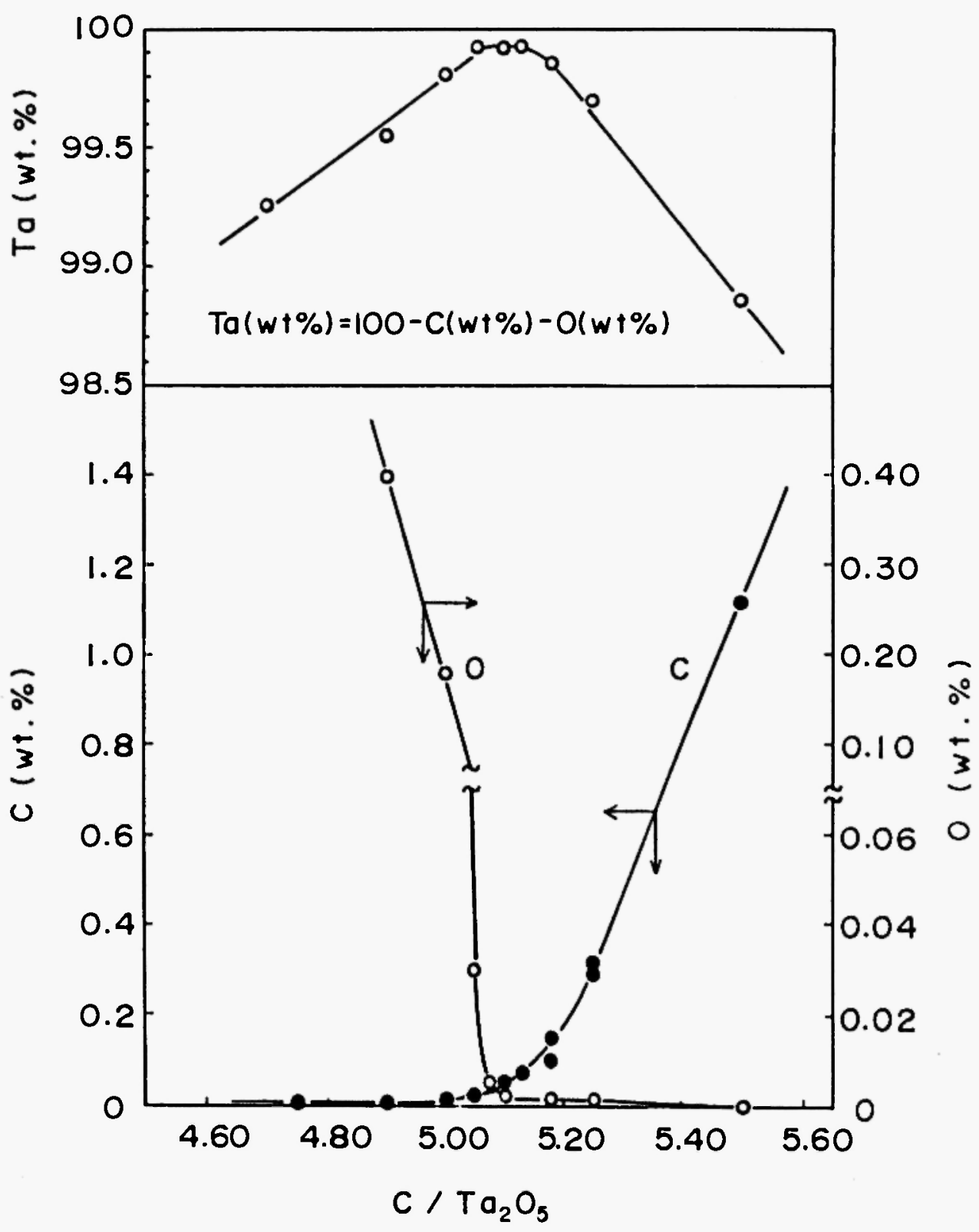

Fig. 25 Dependence of Ta, $\mathrm{C}$ and $\mathrm{O}$ contents of the products on $\mathrm{C} / \mathrm{Ta}_{2} \mathrm{O}_{5}$ at $3100^{\circ} \mathrm{C}$ (reaction time $10 \mathrm{~min}$.) 
of 10 minutes. Tantalum content shown in this figure is estimated by the following equation:

$$
\mathrm{Ta}(w \mathrm{t} . \%)=100-\mathrm{C}(w \mathrm{t} . \%)-0(w \mathrm{t} . \%)
$$

When mixing ratio is less than about 5.15 , the content of the residual carbon in the product is low, and only $400 \sim 500 \mathrm{ppm}$ at the mixing ratio of 5.10 to 5.15 . As the mixing ratio increases. however, a rise in the residual carbon is observed. On the other hand, the residual oxygen content is as low as $40 \sim 60 \mathrm{ppm}$ when the ratio exceeds 5.10, and the oxygen content increases rapidly when the ratio is less than 5.10; at 5.00. more than 1000 ppm of residual oxygen is observed. Therefore, the optimum mixing ratio is approximately $5.10 \sim 5.15$, which is somewhat greater than the stoichiometric ratio of 5.00. In this case, the tantalum content in the reduction product is estimated to be $99.93 \sim 99.94 \%$, see Fig. 25.

The recovery of tantalum is about $70 \sim 80 \%$. This is due to the scattering loss of the sample material during the time spent to melt down the briquette.

The reasons why the optimum mixing ratio is somewhat greater than the stoichiometric ratio are considered to be as follows: Peaks of $\mathrm{Ta}_{2} \mathrm{C}$ and $\mathrm{C}$ are observed in the $\mathrm{X}$-ray diffraction pattern of the scattered material from the briquette. Thus, there is a shortage of carbon in the sample material while reduction is proceeding.

According to the analytical result of tantalum pentoxide by Klopp et al. /30/. the quantity of oxygen combined with 2 atoms of tantalum is somewhat greater than the stoichiometric quantity, 5 atoms, and is estimated as $\mathbf{5 . 0 8}$ atoms.
Thus, the composition of tantalum oxide used as the sample material in this work is considered to be $\mathrm{Ta}_{2} \mathrm{O}_{5} .08$, not $\mathrm{Ta}_{2} \mathrm{O}_{5}$. Therefore, the carbon mixing ratio should be somewhat greater than 5 and the optimum ratio is about 5.10.

\section{B.2. The effect of reaction time}

Dependence of the tantalum. carbon and oxygen contents of the products on the reaction time is shown in Fig. 26. These results are for briquettes with an optimum mixing ratio of 5.13 and reduced at $3100^{\circ} \mathrm{C}$. Upon application of the plasma-arc, the sample melts and forms a button with $60 \sim 70$ seconds. During this period the reduction proceeds rapidly and the tantalum content approaches $\mathbf{9 9 . 5 \%}$. Hence, the carbothermic reduction finishes practically at the reaction time of zero. This period is considered to be the reduction step of the molten tantalumoxide (the melting point of $\mathrm{Ta}_{2} \mathrm{O}_{5}$ is $1872^{\circ} \mathrm{C}$ ) with solid carbon. In this figure, the contents of tantalum, residual carbon and oxygen in the reduction product after the zero reaction time are shown. When the reaction time increases to up to 6 minutes, the contents of carbon and oxygen decreases slowly. And when the time exceeds 10 minutes, the contents of carbon and oxygen reach $400 \sim 500$ ppm and 50 ppm, respectively. Oxygen content is about one tenth of carbon content. However, further reduction of oxide does not occur when the reaction time exceeds 10 minutes. In this step, carbon and oxygen in molten tantalum react and are removed in the form of $\mathrm{CO}$.

The explanation for the stagnation of deoxidation and decarburization when the reaction time exceeds 10 minutes is presented 


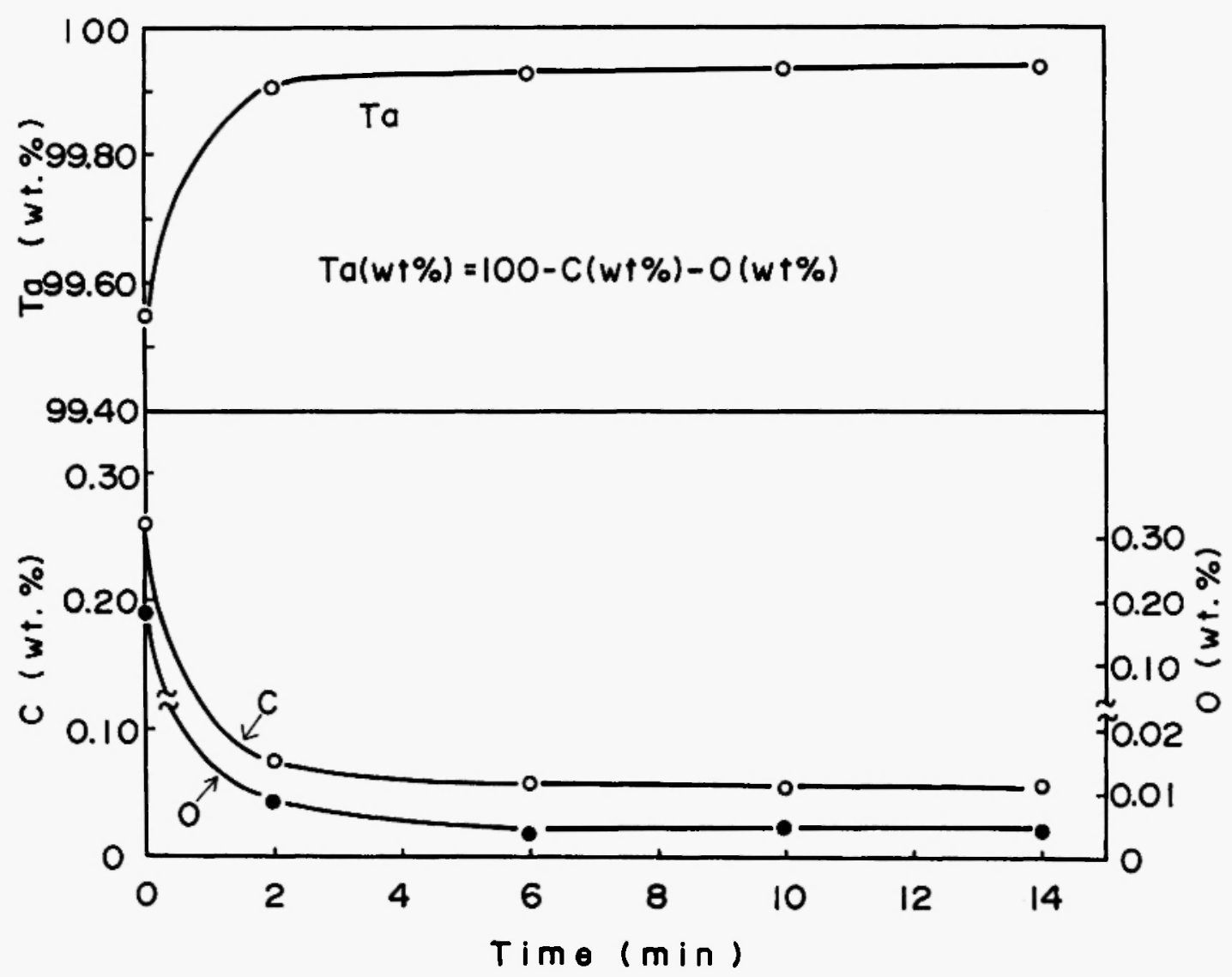

Fig. 26 Dependence of $\mathrm{Ta}, \mathrm{C}$ and $\mathrm{O}$ contents of the products on the reaction time at $3100^{\circ} \mathrm{C}\left(\mathrm{C} / \mathrm{Ta}_{2} \mathrm{O}_{5} 5.13\right)$

with the ald of the above-mentioned report by Klopp et al. /30/. Carbon dissolved in molten tantalum is stable. When oxygen is contained in tantalum at high temperature, carbon is removed from the metal by formation of $\mathrm{CO}$. Furthermore, the remaining oxygen in tantalum is considered to vaporize forming mostly tantalum suboxide, TaOx. When the content of oxygen is small, however, the vapor pressure of the oxddes is low and then the removal of carbon becomes difficult. Klopp et al. /30/ mixed $\mathrm{Ta}_{2} \mathrm{O}_{5}$ with $\mathrm{TaC}$ and heated in a high vacuum of about $10^{-7}$ torr at $2200^{\circ} \mathrm{C}$ for 4 hours. The best reduction product contained only 400 ppm of carbon and $46 \mathrm{ppm}$ of oxygen. The remaining carbon and oxygen were considered to be in the equillbrium state.

In this work the heating temperature is much higher and is about $3100^{\circ} \mathrm{C}$. Therefore, by the extremely short reaction time, the contents of the residual carbon and oxygen reach the same order as those of Klopp et al. /30/. In this case, the reaction of deoxidation and decarburization is shown as follows:

$$
C(\ln \mathrm{Ta})+\mathrm{O}(\ln \mathrm{Ta})=\mathrm{CO}
$$

where, the equilibrium constant $K$ equals $\mathrm{P}_{\mathrm{co}} /[\mathrm{C}] \cdot[\mathrm{O}]$. The free energy change of this 
reaction up to the melting temperature of tantalum is reported as follows:

$$
\Delta \mathrm{G}^{\mathrm{O}}=65000-28.3 \mathrm{~T}(\mathrm{cal} / \mathrm{mol} \text { oxygen })
$$

Therefore, when $\mathbf{P}_{\text {co }}$ is kept constant. $K$ should increase with the increase of reaction temperature and the residual carbon and oxygen in tantalum should decrease. Furthermore, the concentration product of carbon and oxygen. $[\mathrm{C}]$. $[\mathrm{O}]$, in tantalum is considered to be directly proportional to the pressure of $\mathrm{CO}$, and the quantity of carbon and oxygen decreases with $\mathrm{P}_{\mathrm{co}}$.

If we assume that the residual carbon and oxygen in this work are in the equilibrium state not-withstanding the short reaction time, these values are somewhat large because the reduction temperature is far higher than that of Klopp et al. /30/. The pressure of $\mathrm{CO}$ around the sample is considered to be small due to argon gas injection into the furnace at a high flow rate, but to be somewhat larger compared with the high vacuum of the experiment by Klopp et al. Therefore, the residual carbon and oxygen contents in Fig. 25 are somewhat large for high temperature reaction of plasma-heating.

B.3 Impurtties in the reduction products

The sample material, $\mathrm{Ta}_{2} \mathrm{O}_{5}$, contains $100^{-}$ $200 \mathrm{ppm}$ of $\mathrm{Ca}, 10 \sim 100 \mathrm{ppm}$ of Si, Mg, Fe and 1 $10 \mathrm{ppm}$ of $\mathrm{Cu}$ as impurities, respectively. In the products, however, $\mathrm{Cu}$ content is almost zero and the contents of every other impurity are much less and under $10 \mathrm{ppm}$. Thus, a refining effect is expected in the plasma-arc heating process, see Table 3.
B.4. X-ray diffraction analysis of the reduction products

$X$-ray diffraction patterns for the products of various carbon mixing ratio are presented in Fig. 27. Peaks $A$ and $B$ indicate Ta and $\mathrm{Ta}_{2} \mathrm{C}$, respectively. As shown in this figure, the tantalum peaks are only obtained when the mixing ratio is 5.10 corresponding to the values of chemical analysis. When the ratio exceeds 5.10, peaks of Ta $2 \mathrm{C}$ are observed and intensified with the increase of the mixing ratio. On the other hand, when the ratio decreases to 5.00 and 4.90 , the locations of the peaks are slightly shifted to the small angle of about $0.2 \sim 0.6$ degrees from those of tantalum, and these are indicated as $\mathrm{A}^{\circ}$ peaks. Oxygen solubility in tantalum metal is ten times more than that of carbon. see Table 4/32-34/.

TABLE 4

The solubility of carbon and oxygen in tantalum

\begin{tabular}{|l|l|l|}
\hline Temp. $\left({ }^{\circ} \mathrm{C}\right)$ & {$[\mathrm{C}]$ (wt. \%) } & {$[\mathrm{O}]$ (wt. \%) } \\
\hline 1000 & 0.005 & 0.27 \\
1500 & 0.011 & 0.33 \\
1800 & & 0.53 \\
2000 & 0.18 & \\
2600 & 0.42 & \\
\hline
\end{tabular}

Therefore, the $A^{\prime}$ peaks are considered to be tantalum peaks which have strains produced in the lattice by the pressure of oxygen as a solid solution. When the product contains some carbon. it will form phases of tantalum metal and carbide, $\mathrm{Ta}_{2} \mathrm{C}$, corresponding to the eutectic composition.

Furthermore, the relation between the $\mathrm{X}$-ray diffraction pattern and the reaction time was 


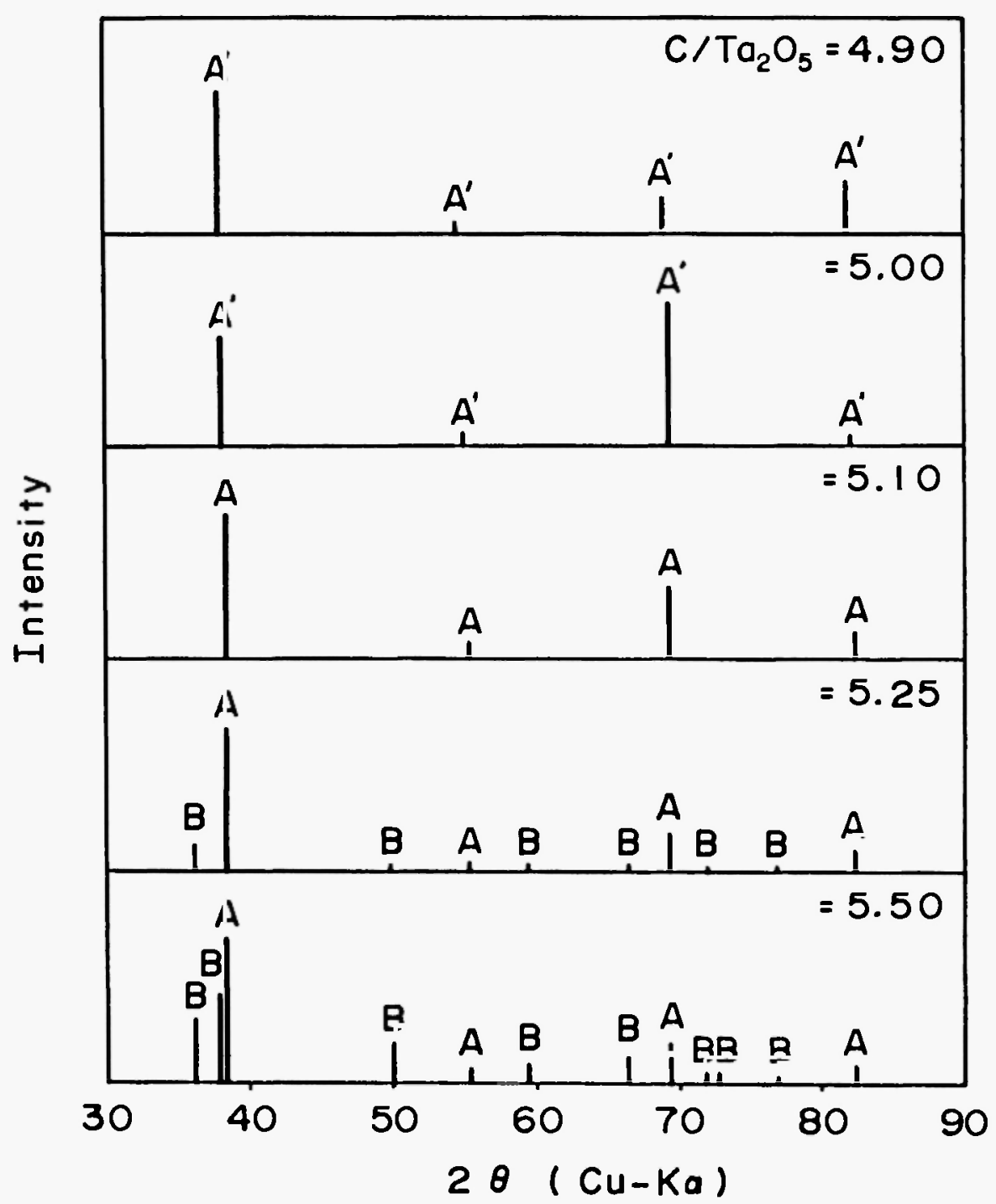

Fig. 27 Dependence of the $X$-ray diffraction pattern of the products on $\mathrm{C} / \mathrm{Ta}_{2} \mathrm{O}_{5}$ (temperature $3100^{\circ} \mathrm{C}$, time $10 \mathrm{~min}$ ) $\mathrm{Ta}_{2} \mathrm{C}, \mathrm{A}^{\prime}$ : Ta (shifted)

examined. Sample materials with an optimum mixing ratio of 5.10 were reduced at $3100^{\circ} \mathrm{C}$ for $\mathrm{O}$. 2. 6 and 10 minutes. When the reaction time is zero, peaks of shifted $\mathrm{Ta}$ and $\mathrm{Ta}_{2} \mathrm{C}$ are obtained. In the case of 2 minutes, peaks of Ta change to those of pure metal. With increase in the reaction time, peaks of Ta are intensifled and those of $\mathrm{Ta}_{2} \mathrm{C}$ are weakened. In the case of 10 minutes, only the peaks of Ta are observed, see Fig. 28. This corresponds with Fig. 26.

B.5. Reduction product hardness measurement

Hardness of metals such as $\mathrm{V}, \mathrm{Nb}, \mathrm{Ta}$ increases rapidly when small amounts of carbon or oxygen are present. 


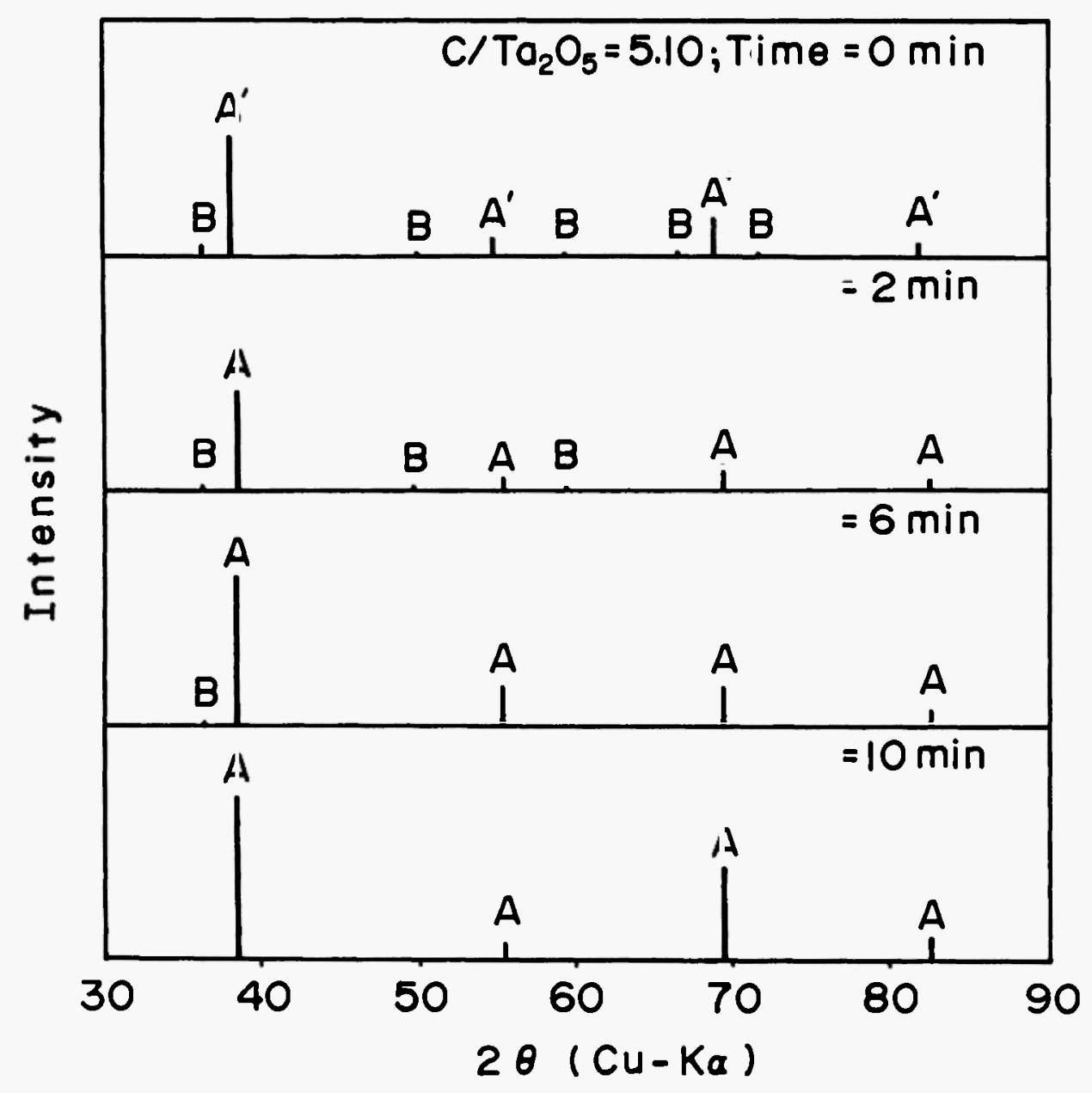

Fig. 28 Dependence of the X-ray diffraction pattern of the products on the reaction time (temperature $3100^{\circ} \mathrm{C}, \mathrm{C} / \mathrm{Ta}_{2} \mathrm{O}_{5}$ 5.10) A: Ta, B: Ta2C. A': Ta (shifted)

The Vickers hardness of the products reduced at $3100^{\circ} \mathrm{C}$ for 2,6 and 10 minutes was measured.

Fig. 29 shows the dependence of the Vickers hardness number of the products on the mixing ratio. The minimum hardness number of the products occurs at the ratio of $5.10-5.15$ and colncides with a maximum content of tantalum. The minimum hardness value is about 170 when the reaction time is 10 minutes. As shown in this figure when the ratio decreases from 5.10 to 5.00, the hardness number greatly increased. Although the oxygen content at the ratio of 5.10 is about 50 ppm, that of the ratio of $\mathbf{5 . 0 0}$ increases to about 1000 ppm, see Fig. 25. Therefore, oxygen is considered to have a far greater effect than carbon on the product hardness.

Following a fusion treatment in the plasmaarc furnace, commercially available tantalum metal of $99.9 \%$ purity gives a Vickers hardness of 104. indicated with a dotted line in Fig. 29. However, in this work, the minimum value is 170 and this larger value is considered to be due to the 


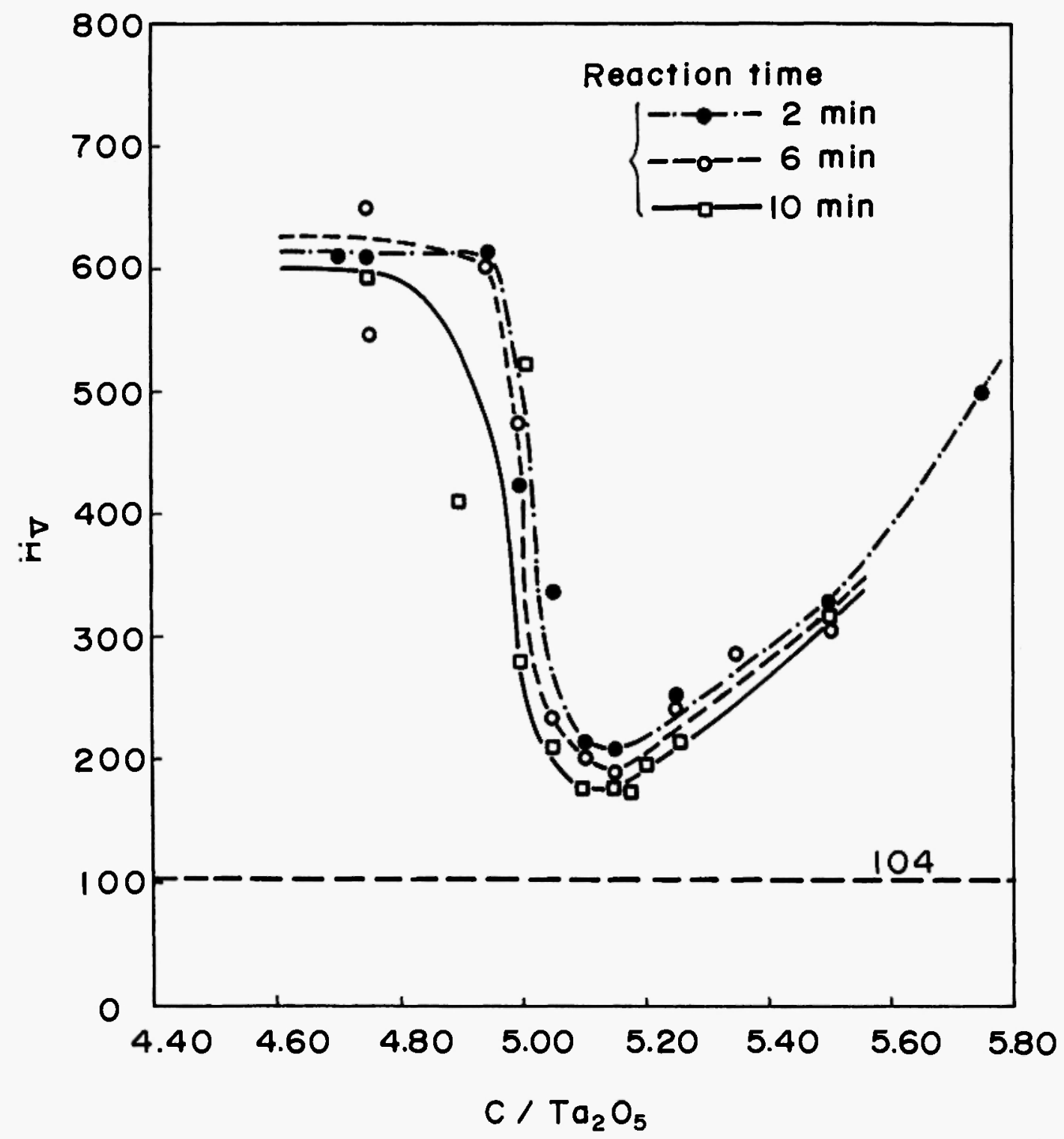

Fig. 29 Dependence of Vickers hardness of the products on $\mathrm{C} / \mathrm{Ta}_{2} \mathrm{O}_{5}$ (temperature $3100^{\circ} \mathrm{C}$ )

carbon content of about 500 ppm in the product. Vaughan et al. /32/ investigated the dependence of the hardness of tantalulm of carbon content. According to them, the hardness number increases with the increase of carbon content, and when the carbon content is about 500 ppm, Vickers hardness number is 190.
Furthermore, dependence of hardness of reaction time for products of the optimum mixing ratio was investigated. The hardness of the products at zero reaction time is very large and the hardness number is about 600 due to the remaining oxygen and carbon. As the reduction advances, the hardness decreases. When the 


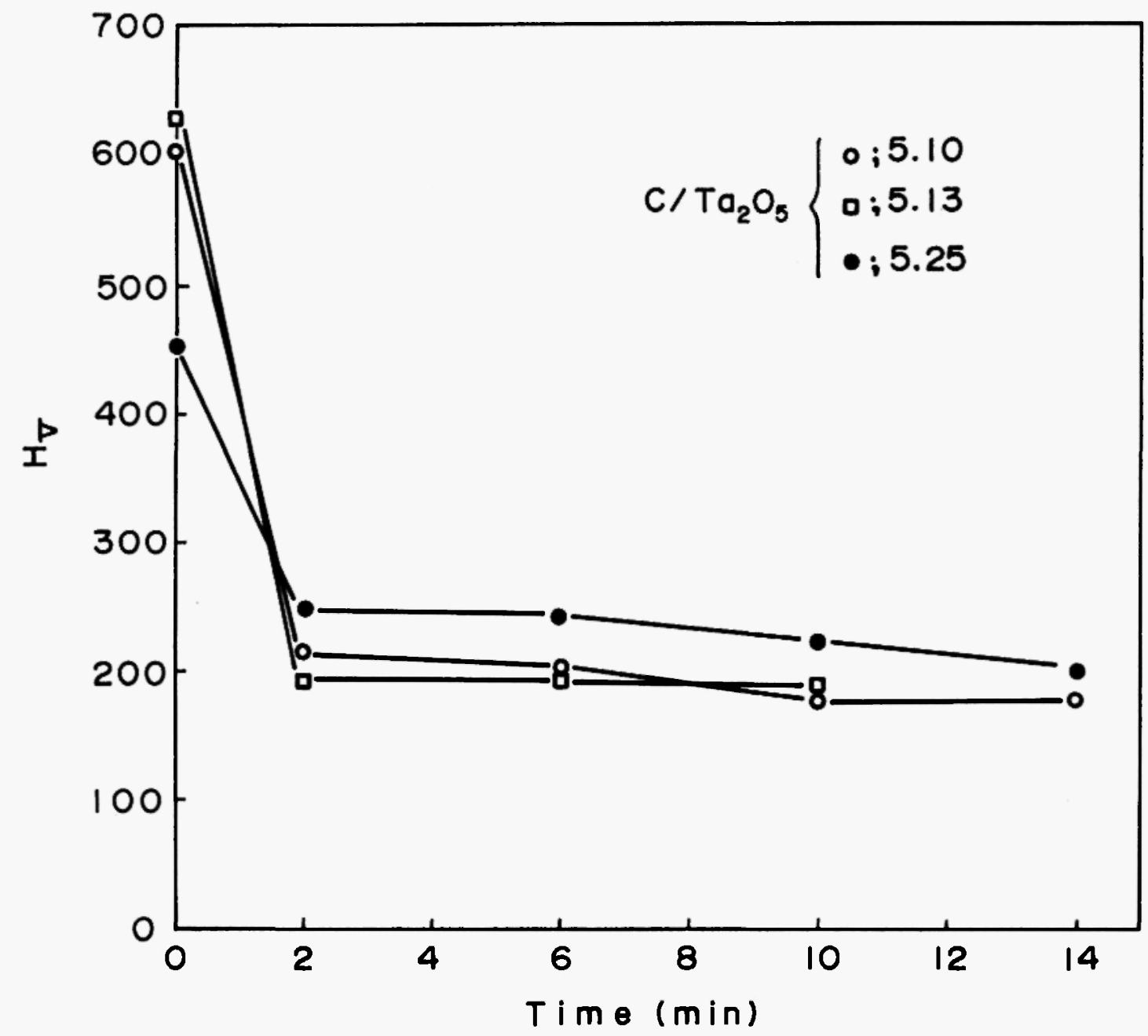

Fig. 30 Dependence of Vickers hardness of the products on the reaction time (temperature $3100^{\circ} \mathrm{C}$ )

reaction time exceeds 10 minutes, however, the hardness number becomes constant and iq about 170, see Fig. 30.

B.6. Microscopic examination of the structure and the qualitative EPMA analysis

The structure of the sample reduced for 30 seconds of plasma-arc heating (namely, the state before melt down) is coarse as a whole and many black regions are observed, see Photo 8 , due to insufficient reduction. A qualitative EPMA analysis for the matrix surrounding this black region was performed. Photo. 9 shows the analysis results of tantalum, carbon and oxygen when the electron beam is scanned across the sample as indicated by the white center line. As shown in this photograph. the carbon content is large but tantalum and oxygen are scarcely found in the black region. In the neighborhood of this black region, the oxygen content is relatively large and 
this is considered to be a form of oxide. In the peripheral part far from this region, however, the tantalum content is large and that of carbon or oxygen is relatively small, and reduction is considered to be almost completed in this part. Based on the above-mentioned results, the reduction reaction before melt down is considered to be the reaction of liquid tantalum oxide with solid carbon.

Photo. 10 shows the microstructures of the sample at the optimum mixing ratio of 5.10

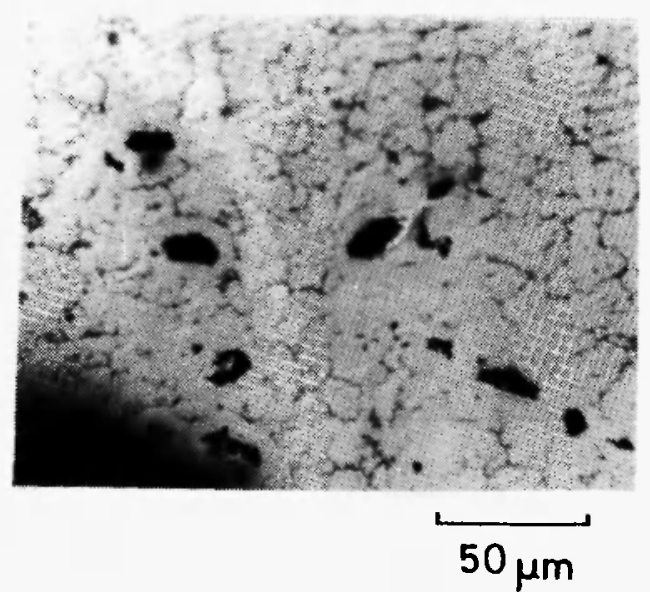

Photo. 8 Microstructure of the sample before the melting down $\left(\mathrm{C} / \mathrm{Ta}_{2} \mathrm{O}_{5}=5.10\right.$ : heated for $30 \mathrm{sec}$.)

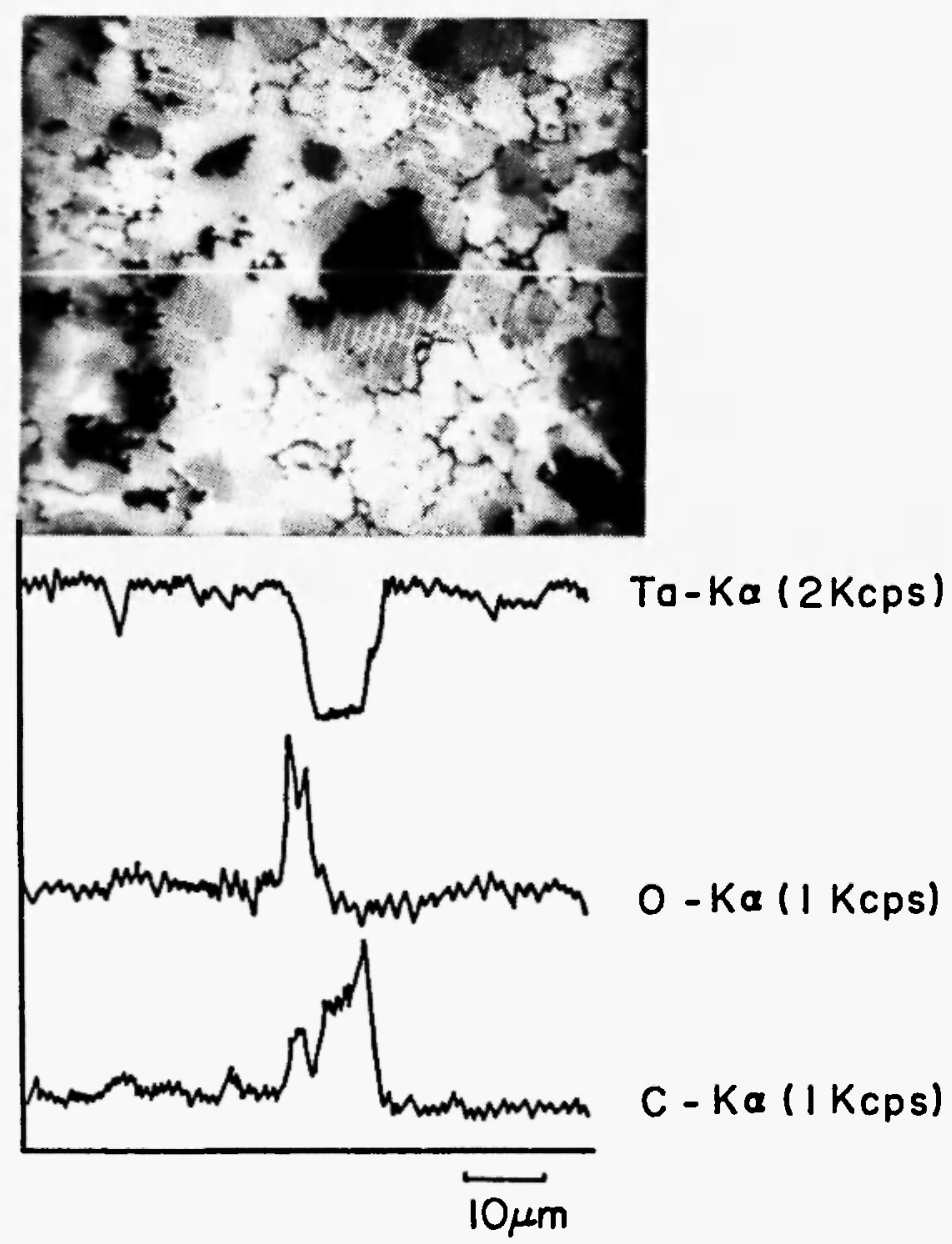

Photo. 9 Line scanning profiles by EPMA for $\mathrm{Ta}, \mathrm{O}$ and $\mathrm{C}$ of the sample shown on Photo. 2 

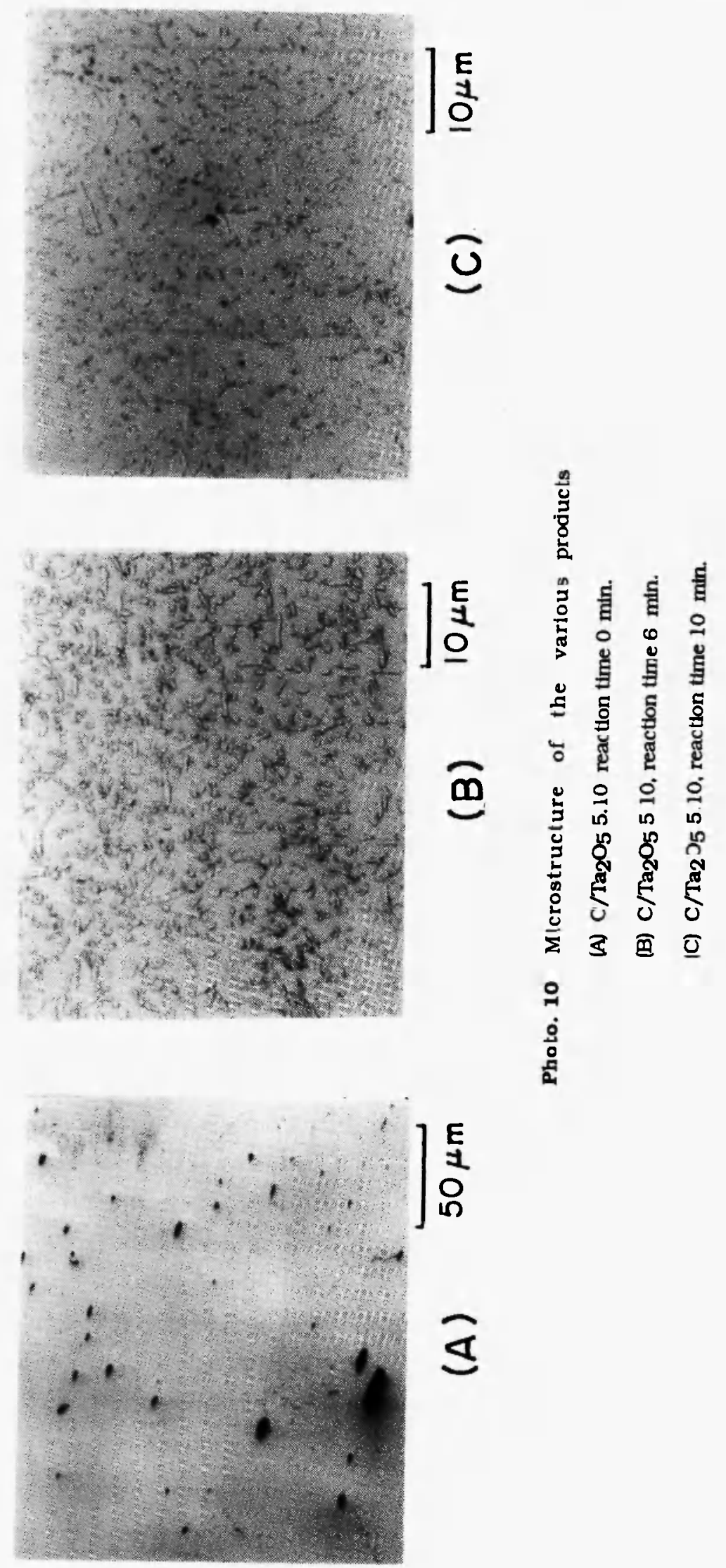
reduced 0 and 6 minutes, respectively. Photo. 10 (A) shows the microstructure of the sample at zero reaction time (namely, just after melt down). There are many black spots in the fine structure. But these spots are found to be tantalum carbide, $T a_{2} C$, by EPMA analysis and $X$-ray diffraction.

In Photo. 10(B), the sample was reduced for 6 minutes: The reduction proceeded fairly well, and a uniform dendritic structure is observed. The difference of carbon and oxygen contents between the dendritic region and the surrounding phase was not observed in the EPMA analysis. As reduction advances still more, the dendritic structures become finer.

The reduction products in this study contain a far smaller quantity of the remaining oxygen, 40 $\sim 60 \mathrm{ppm}$, than the full amount of its solubility. Conversely, the content of the remaining carbon is about $500 \mathrm{ppm}$ and this is greater than its solubility in the range of a comparatively low temperature of about $1000^{\circ} \mathrm{C}$. Therefore, the precipitation of carbide is expected. On the other hand. it is reported that the solubility of carbon in tantalum increases tolerably with rise in temperature /33/. In this work. the sample material is rapidly cooled by blowing in argon and precipitation of carbide is considered to be prevented.

\section{CONCLUSIONS}

The carbon reduction of vandium pentoxide $"$ and tantalum pentoxide was investigated in a plasma-arc furnace. The sample was a mixture of vanadium pentoxide or tantalum pentoxide and graphite, vacuum pressed under a pressure of 6 ton $/ \mathrm{cm}^{2}$ into a briquette. Green briquette and the briquette sintered at $700 \sim 1000^{\circ} \mathrm{C}$ for 1 hour under Ar atmosphere were used.

Pure argon or Ar- $\mathrm{H}_{2}$ mixture $\left(\mathrm{H}_{2}=5 \sim 25\right.$ vol\%) were used as the arc gas.

The results are as follows:

For V:

1. The optimum mixing ratio of carbon and vandium pentoxdde, $\mathrm{C} / \mathrm{V}_{2} \mathrm{O}_{5}$, is about 4.5 and is smaller than the stoichiometric ratio of 5 . When the mixing ratio is less than 4.5 , oxygen remaining in the product increases, while vanadium carbide increases when the ratio is greater than 5.

2 The sample, which weighed $3.5 \mathrm{~g}$, is fused within 45 seconds by plasma-arc heating and reduction of vanadium pentoxide proceeds rapidly to approximately $90 \% \mathrm{~V}$ in this period. The reduction that follows in the molten state is slow. Within 10 minutes, the maximum vanadium content reaches $96 \%$. Longer times of plasma-arc heating are almost useless for reduction.

3 Preliminary sintering of the briquette results in good recovery of vanadium due to the diminished loss of the sample under the plasma flame.

4 An increase in vanadium content is not observed as the temperature is increased from 2100 to $2800^{\circ} \mathrm{C}$.

5 The hardness of the product with a maximum vanadium content is about $\mathrm{H}_{\mathrm{V}} 290$ and is much larger than that of vanadium metal due to the remaining oxygen, in particular.

6 The presence of well-developed, dendritic, primary crystals is observed in the reduction product high in vanadium content. In this 
study, pure vanadium metal is not obtained due to the strong affinity of vanadium for carbon or oxygen. However, vanadium of $96 \%$ purity is produced within a short time.

7. To prepare high - purity vanadium metal, the investigation of deoxidation and decarburization of a crude vanadium containing a small amount of carbon and oxygen, obtained by carbothermic reduction of vanadium oxide, was made by $\mathrm{Ar}-\mathrm{H}_{2}(5 \sim 25$ vol.\%) plasma-arc smelting as the second step smelting.

8 Carbon and oxygen contents in a crude vanadium obtained by the carbothermic reduction of vanadium oxide were dependent and controlled on the mixing ration, $\mathrm{C} / \mathrm{V}_{2} \mathrm{O}_{5}$.

9 Remarkable deoxidation from a crude vanadium was found in the $\mathrm{Ar}-\mathrm{H}_{2}$ plasma arc smelting, but decarburization was insufficient, as expected by the thermodynamical calculations.

10. Massive vanadium metal of about $99.6 \%$ purity with a hardness of $\mathrm{H}_{V}=180$ was obtained by Ar-H2 (25 vol.\%) plasma-arc treatment of a crude vanadium with a high oxygen and low carbon content.

11. Deoxidation of reaction was mainly due to the reaction between oxygen in vanadium and hydrogen molecule and/or atom at high temperature, and the contribution of metal suboxide volatilization to deoxidation was small so that loss of vanadium was reduced. Therefore, over all metal yields of above $85 \%$ were typical.

\section{For Ta:}

12. The optimum mixing ratio of carbon and tantalum pentoxdde, $\mathrm{C} / \mathrm{Ta}_{2} \mathrm{O}_{5}$, is $5.10 \sim 5.15$ and is somewhat greater than the stolchlometric ratio of 5 . When the mixing ratio is less than 5.10 , the oxygen remaining in the product increases, while the tantalum carbide, $\mathrm{Ta}_{2} \mathrm{C}$, Increases when the ratio is greater than 5.25. Argon was used as the arc gas.

13. The sample, weighing $7 \mathrm{~g}$ is fused within 60 70 seconds by plasma-arc heating and the reduction of molten tantalum oxide with solid carbon proceeds rapidly to approximately 99.5\% Ta during this period. The reduction that follows in the molten state is slow. Within about 10 minutes, the maximum tantalum content reaches $99.9 \%$ and the oxygen and carbon remaining in the product are 50 ppm and $400 \sim 500$ ppm respectively. Longer times of plasma-arc heating are almost useless for the reduction.

14. Impurities in the sample of tantalum pentoxide are small amounts of $\mathrm{Ca}, \mathrm{SI}, \mathrm{Fe}, \mathrm{Mg}$ and $\mathrm{Cu}$. These impurities diminish considerably by plasma-arc reduction.

15. The hardness of the product with a maximum tantalum content is about $\mathrm{H}_{\mathrm{V}} 170$ and is somewhat larger than that of tantalum metal due to the remaining carbon, in particular.

16. The presence of the fine, dendritic structure is observed in the reduction product high in tantalum content. In this tantalum metal, the remaining carbon and oxygen are considered to be distributed uniformly as solid solutions.

In this study, tantalum metal is produced within a short time. Its purity is over $99.9 \% \mathrm{Ta}$ and the remaining oxygen and carbon are only $50 \mathrm{ppm}$ 
and 500 ppm, respectively.

In combination with a suitable refining process to diminish the remaining oxygen and carbon, plasma-arc reduction is considered to be a useful process for the production of massive tantalum metal.

\section{ACKNOWLEDGEMENT}

The author is indebted to his colleague, Mr. Koji Mimura, for his great contribution to the investigation. The author wishes to express his gratitude to Dr. C.K. Gupta for publication of this paper.

\section{REFERENCES}

1. DICTIONARY OF PHYSICS AND CHEMISTRY, (Rikagaku Jiten) 4 th ed., 757. Iwanaml. (1988).

2 TYLER, P.M., J. Metals, 13:15 (1988).

3 SAYCE, I.G., Advances in Extractive Metallurgy and Refining, 241, M.J. Jones, (1972).

4 HAYAKAWA, Y. and MATSUMOTO. O., Plasma Chemistry and its Application, 111. Shokado (1971).

5 AKASHI, K. and ISHIZUKA, R., Kinozuko (Metals). 43:50 (1973).

6 KUMAMOTO, Y., New Metals Databook (ShinKinzoku Databook). 296. Agne (1977).

7. MCKECHNIE, R.K. and SEYBOLT, A.V., J. Electrochem Soc., 97:311 (1950).

8 BEARD, A.P. and CROOKS, D.D., ibid., 101:597 (1954).

9 CARLSON, O.N. and OWEN. C.V., ibid, 108:88 (1961).
10. KROLL, W.J. and SCHLECHTON, A.W., ibid., 83:247 (1948).

11. TAKEUCHI, S. et al., J. Electrochem. Soc. Japan (Denkikagaku), 33:713 (1965).

12. ISHIZUKA, R, AKASHI, $K$. and EGAMI, I., J. Institute of Industrial Science (SeisanKenkyu). Tokyo University, 22:370 (1970).

13. KUBASCHEWSKI, $O$. et al., Metallurgical Thermochemistry. 421. Pergamon Press. (1967).

14. ARAKI, T. et al., The Fundamentals for the Smelting of Iron and Steel. Tekko-Seiren no Kiso, 90. Asakura Shoten. (1971).

15. WORRELL, W.L. and CHIPMAN, J., Trans. AlME, 230: 1682, (1964).

16. KAINUMA. N. et al., The Summary of the 1977 Spring Meeting of Nippon Kinzoku Gakkai, 70, (1977).

17. STORMS, E.K. and MCNEAL, R.J., J. Phys. Chem., 66:1401. (1962).

18. ALEXANDER, D.G. and CARLSON, O.N., Met. Trans.. 2:2805, (1971).

19. JANAF : Thermochemical Tables. 2nd Ed. (1971).

20. MAKUNIN, M.S., POLYAKOV, A. YU. and SAMARIN, A.M., Izv. Akad. Nauk. SSSR. Otdel. Tekh. Nauk, 2:35 (1959).

21. THOMPSON. R.W. and CARLSON, O.N., J. Less-Common Metals, 9:354, (1965).

22. ROSTKER, W. and YAMAMOTO, A.S., Trans. ASM, 47:1002, (1955).

23. SEYBOLT, AU. and SUMISON, H.T., Trans. AIME, 197:292, (1953).

24. ONO, K., UEDA. Y. and MORIYAMA. J., J. Japan Inst. Metals, 43:715, (1979).

25. BREWER, L. and ROSSENBIATT, G.M., Trans. AlME, 224: 1268, (1962). 
26. WANG. C.T., BAROCH, E.F., WORCESTER, S.A. and SHEN, Y.S., Met. Trans. 4:1683, (1970).

27. SHIN-KINZOKU KYOKAI (ed.), Tantalum and Nioblum, 40, Shin-Kinzoku Kyokal (Soclety of New Metals). (1975).

28. Hampel, c.a., Rare Metals Handbook, 2nd ed., 472, Reinhold Publ. Co., (1961).

29. KROLL. W.J. and SCHLECHTON, A.W., Trans. Electrochem. Soc., 83:247, (1948).

30. KLOPP, W.D., MAYKUTH, D.J., OGDEN, H.R. and JAFFEE., R.I., Trans. Met. Soc. AIME,
218:971, (1960).

31. FROMM, E., J. Less-Common Metals, 14:113. (1968).

32. VAUGHAN, D.A., STEWART, O.M. and SCHWARTZ, C.M., Trans. Met. Soc. AIME, 221:937, (1961).

33. FROMM, E. and ROY. U.. J. Less-Common Metals, 8:73, (1965).

34. JEHN, H. and OLZI, E.J., J. Less-Common Metals, 27:297, (1972). 